\title{
Cohesive and mixed sediment in the Regional Ocean Modeling System (ROMS v3.6) implemented in the Coupled Ocean-Atmosphere-Wave-Sediment Transport Modeling System (COAWST r1234)
}

\author{
Christopher R. Sherwood ${ }^{1}$, Alfredo L. Aretxabaleta ${ }^{1}$, Courtney K. Harris ${ }^{2}$, J. Paul Rinehimer ${ }^{2, a}$, Romaric Verney ${ }^{3}$, \\ and Bénédicte Ferré ${ }^{1, b}$ \\ ${ }^{1}$ U.S. Geological Survey, 384 Woods Hole Road, Woods Hole, MA 02543-1598, USA \\ ${ }^{2}$ Virginia Institute of Marine Science, College of William \& Mary, Gloucester Point, VA 23062, USA \\ ${ }^{3}$ IFREMER, Plouzane, France \\ ${ }^{a}$ currently at: WEST Consultants, Bellevue, WA 98055, USA \\ ${ }^{b}$ currently at: CAGE-Centre for Arctic Gas Hydrate, Environment, and Climate; Department of Geosciences, \\ UiT The Arctic University of Norway, 9037 Troms $\varnothing$, Norway
}

Correspondence: Christopher R. Sherwood (csherwood@usgs.gov)

Received: 25 October 2017 - Discussion started: 1 December 2017

Revised: 26 March 2018 - Accepted: 11 April 2018 - Published: 14 May 2018

\begin{abstract}
We describe and demonstrate algorithms for treating cohesive and mixed sediment that have been added to the Regional Ocean Modeling System (ROMS version 3.6), as implemented in the Coupled Ocean-Atmosphere-WaveSediment Transport Modeling System (COAWST Subversion repository revision 1234). These include the following: floc dynamics (aggregation and disaggregation in the water column); changes in floc characteristics in the seabed; erosion and deposition of cohesive and mixed (combination of cohesive and non-cohesive) sediment; and biodiffusive mixing of bed sediment. These routines supplement existing noncohesive sediment modules, thereby increasing our ability to model fine-grained and mixed-sediment environments. Additionally, we describe changes to the sediment bed layering scheme that improve the fidelity of the modeled stratigraphic record. Finally, we provide examples of these modules implemented in idealized test cases and a realistic application.
\end{abstract}

Copyright statement. The authors' copyright for this publication is transferred to the US government.

\section{Introduction}

\subsection{Motivation}

Fine cohesive sediment (mud) is present in almost every coastal environment and influences water clarity, benthic habitats, shoaling of harbors and channels, storage and transport of nutrients and contaminants, and morphologic evolution of wetlands, deltas, estuaries, and muddy continental shelves (Winterwerp and van Kesteren, 2004; Edmonds and Slingerland, 2010; Caldwell and Edmonds, 2014; Mehta, 2014; $\mathrm{Li}$ et al., 2017). The properties and behavior of mud depend on more than the size, shape, and density of the individual particles, so they are more difficult to characterize and model than properties of non-cohesive material like sand. Cohesive sediment often forms flocs that have lower densities, larger diameters, and faster settling velocities than the primary particles. Acoustic and optical sensors respond differently to suspensions of flocculated sediment compared with similar mass concentrations of unflocculated particles, and these responses have important influences on observations of suspended sediment mass concentrations, especially in estuaries (for example, McCave and Swift, 1976; McCave, 1984; Eisma, 1986; Hill and Nowell, 1995; Winter- 
werp, 1999, 2002; Winterwerp et al., 2006; Xu et al., 2008, 2010; Verney et al., 2011; Slade et al., 2011; MacDonald et al., 2013; Thorne et al., 2014).

Cohesive sediment beds are distinguished by generally finer sediment, including some clay content, are often poorly sorted, and have low bulk density (high water content). Cohesive beds have a tendency for bulk responses to bottom stress, rather than individual particle responses. Cohesive beds have rheological properties that can range from fluids to Bingham plastics to granular materials and may change with time in response to changes in water content, biochemical processes, and fluid or geomechanical stresses (Dyer, 1986; Whitehouse et al., 2000; Winterwerp and Kranenburg, 2002; Winterwerp and van Kesteren, 2004; Maa et al., 2007; Knoch and Malcherek, 2011; Mehta, 2014).

Sediment transport in coastal ocean models is sensitive to the representation of fine-scale stratigraphy because evolving seabed properties determine what sediment is exposed to the water column and available for transport. Small-scale stratigraphy and grain size distribution at the sediment-water interface also influence the grain roughness of the seabed, affect the type of small-scale roughness (biogenic features and ripples) present on the bed, and control properties like acoustic impedance of the seafloor. Biodiffusion influences stratigraphy by reducing gradients in grain size and other bed properties and by mixing materials from deeper in the bed to closer to the surface, where they may be more susceptible to transport.

\subsection{Previous modeling efforts}

Amoudry and Souza (2011) surveyed regional-scale sediment transport and morphology models and found that one of the shortcomings was the treatment of cohesive and mixedsediment models. The water-column behavior of cohesive sediment (e.g., flocculation, disaggregation, and settling) and the consolidation of settling particles to form a cohesive bed has been modeled mostly with one-dimensional vertical (1DV) models or with empirical formulae that allow particle settling velocity to vary as a function of salinity (Ralston et al., 2012) or suspended sediment concentration (e.g., Mehta, 1986; Lick et al., 1993; Van Leussen, 1994; Lumborg and Windelin, 2003; Lumborg, 2005; and Lumborg and Pejrup, 2005). Mietta et al. (2009) have demonstrated the effect that $\mathrm{pH}$ and organic matter content have on mean floc size and settling velocity. The primary dynamical effect of flocculation is to increase settling velocities, thereby increasing the mass settling flux. This has implications for deposition rates (Mehta et al., 2014). Soulsby et al. (2013) reviewed methods for estimating floc settling velocities and proposed a new formulation that depends primarily on turbulence shear and instantaneous suspended sediment concentration. Spearman et al. (2011) noted that adjustments to settling velocity (e.g., Manning and Dyer, 2007) were able to successfully reproduce floc settling in one-dimensional estu- ary modeling applications. However, approaches that adjust only settling velocity do not allow for an analysis of other characteristics of the suspended particle field, such as particle size and density, which affect acoustic and optical properties, or geochemical properties (water content and surface area). Full floc dynamics have been incorporated in only a few coastal hydrodynamics and sediment transport models. Winterwerp (2002) incorporated his floc model (Winterwerp, 1999) in a three-dimensional simulation of the estuary turbidity maximum (ETM) in the Ems estuary. Ditschke and Markofsky (2008) described formulations in TELEMAC-3D to represent exchanges among size classes from floc dynamics. Xu et al. (2010) added floc dynamics to the Princeton Ocean Model (POM) and simulated the ETM in Chesapeake Bay. Empirical formulae for the erosion of cohesive sediment have been derived from laboratory flume measurements and field experiments (Whitehouse et al., 2000; Mehta, 2014; Mehta et al., 2014). Many have a form similar to the Ariathurai and Arulanandan (1978) equation used in ROMS (Warner et al., 2008), which relates erosional flux $E\left(\mathrm{~kg} \mathrm{~m}^{-2} \mathrm{~s}^{-1}\right)$ to the normalized excess shear stress as $E=E_{0}(1-\phi)\left[\left(\tau_{\mathrm{sf}}-\tau_{\mathrm{c}}\right) / \tau_{\mathrm{sf}}\right]$ when $\tau_{\mathrm{sf}}>\tau_{\mathrm{c}}$, where $E_{0}$ $\left(\mathrm{kg} \mathrm{m}^{-2} \mathrm{~s}^{-1}\right)$ is an empirical rate constant, $\phi\left(\mathrm{m}^{3} \mathrm{~m}^{-3}\right)$ is sediment porosity, $\tau_{\mathrm{sf}}(\mathrm{Pa})$ is the skin-friction component of the bottom shear stress, and $\tau_{\mathrm{c}}(\mathrm{Pa})$ is the critical shear stress for erosion. The erosion of cohesive sediment in some models (for example Delft3D; van der Wegen et al., 2011; Caldwell and Edmonds, 2014) uses a similar formulation subject to a user-specified critical shear stress for erosion. It is recognized that $\tau_{\mathrm{c}}$ may increase with depth in sediment, and erosion rate formulae have been proposed that incorporate depth-dependent profiles for $E_{0}$ and/or $\tau_{\mathrm{c}}$ (Whitehouse et al., 2000; Mehta, 2014). Wiberg et al. (1994) demonstrated the need to account for small-scale stratigraphy to represent bed armoring for a non-cohesive model and did so via a layered bed model that kept track of changes to sediment bed grain size distribution in response to cycles of erosion and deposition. Bed layers have been used to represent temporal changes to bed erodibility for fine-grained sediment, for example by using an age model for the bed (HydroQual, Inc., 2004). Biodiffusion may alter stratigraphy, and there are many 1DV models that treat the diffusive mass flux of sediment and reactive constituents in the bed, mostly motivated by water quality and geochemical concerns (e.g., Boudreau, 1997; DiToro, 2001; Winterwerp and van Kesteren, 2004). Several regional-scale circulation and sediment transport models treat sediment stratigraphy, including ECOMSED (HydroQual, Inc., 2004), ROMS/CSTMS (Warner et al., 2008), Delft3D (van der Wegen et al., 2011), FVCOM, TELEMAC/SISYPHE (Villaret et al., 2011; Tassi and Villaret, 2014), and MARS3D (Le Hir et al., 2011; Mengual et al., 2017) and some have unpublished treatments for cohesive processes. Sanford (2008) pioneered an approach in which the critical shear stress for each bed layer was nudged toward an assumed equilibrium value, and the critical stress 
for erosion of the surface layer alternately became smaller or larger in response to deposition and erosion. We have combined the approach of Sanford (2008) with biodiffusive mixing to represent depth-dependent changes in erodibility. This approach has been implemented in the cohesive bed stratigraphy algorithm in ROMS (described here) and applied by Rinehimer et al. (2008), Butman et al. (2014), and Fall et al. (2014).

\subsection{Goals of the model}

Our goal in developing and refining sediment dynamics in ROMS is to produce an open-source community model framework useful for research and management that combines cohesive and non-cohesive behavior and is suitable for simulating sediment transport, stratigraphic evolution, and morphologic change. Our goal is to develop methods that can be implemented within coastal and estuarine models for application at regional scales, i.e., domains of tens to hundreds of $\mathrm{km}^{2}$ with grid elements of $10-10000 \mathrm{~m}^{2}$ and the ability to resolve timescales ranging from minutes to decades.

\subsection{Objectives and outline of the paper}

The behavior of non-cohesive sediment (sand) in ROMS was described by Warner et al. (2008). ROMS also includes several biogeochemical modules (Fasham et al., 1990; Fennel et al., 2006). New components have since been added, including spectral irradiance and seagrass growth models (del Barrio et al., 2014) and a model for treating the effects of submerged aquatic vegetation on waves and currents (Beudin et al., 2017). The present paper describes new components that model processes associated with cohesive sediment (mud) and mixtures of sand and mud. These components include the aggregation and disaggregation of flocs in the water column, sediment exchange with a cohesive bed in which erosion is limited by a bulk critical shear stress parameter that increases with burial depth, and tracking stratigraphic changes in response to deposition, erosion, and biodiffusive mixing. Our goal is to demonstrate that the algorithms reproduce some of the important behaviors that distinguish cohesive sedimentary environments from sandy ones and to demonstrate their utility for modeling muddy environments. The model processes are presented and discussed in Sect. 2. Additional details on the model implementation and their use in ROMS are presented in the Supplement. Examples of model behavior are presented in Sect. 3, and a realistic application in the York River estuary is presented in Sect. 4. Discussion and conclusions are in Sects. 5 and 6.

\section{Model processes}

Flocculation is represented as a local process of aggregation and disaggregation that moves mass among the floc classes within each model grid cell during a ROMS baroclinic time step. ROMS uses a split time step scheme that integrates over several (ca. 20) depth-averaged (barotropic) time steps before the depth-dependent baroclinic equations are integrated (Shchepetkin and McWilliams, 2005). The subsequent advection and mixing of floc particles is performed along with other tracers (heat, salt, sand, biogeochemical constituents). The water column is coupled with the sediment bed via depositional fluxes determined by near-bed concentrations, settling velocities, and threshold shear stresses and via erosional fluxes determined by bottom shear stresses, bulk and particle critical shear stresses for erosion, and sediment availability in the top active layer (Warner et al., 2008). The distribution of mass among the cohesive classes can change in the bed as flocs are converted to denser aggregates. Deposition and erosion affect the mass of sediment classes in the stratigraphic record, which can also be changed by biodiffusive mixing and a heuristic model of erodibility as a function of time and sediment depth. Each of these processes is described below.

\subsection{Properties of sediment, seafloor, and seabed}

ROMS accounts for two distinct types of sediment: noncohesive sediment (e.g., sand) and cohesive sediment (e.g., mud). The general framework used to represent sediment and the seabed is unchanged from Warner et al. (2008), except that the expanded model requires additional variables to allow for both cohesive and non-cohesive classes. The number of sediment classes is presently limited to 22 of each type by the input-output formats, but is otherwise only constrained by computational resources. Each class must be classified as either non-cohesive or cohesive, and at least one class of one type is required for sediment transport modeling. Each class is associated with properties (diameter, density, critical shear stresses for erosion and deposition, settling velocity) that are specified as input and remain constant throughout the model calculations. Seafloor properties that describe the condition of the sediment surface are stored with spatial dimensions that correspond to the horizontal model domain. Seafloor properties include representative values (geometric means) of sediment properties in the top layer, including grain size, critical shear stress for erosion, settling velocity, and density and properties of the sediment surface, such as ripple height, ripple wavelength, and bottom roughness. Seabed properties (i.e., stratigraphy) are tracked at each horizontal location and in each layer in the bed. The number of layers used to represent seabed properties is specified as input and remains constant throughout the model run. The mass of each sediment class, bulk porosity, and average sediment age is stored for each bed layer. The layer thickness, which is calculated from porosity and the mass and sediment density for each class is stored for convenience, as is the depth to the bottom of each layer. Additional information for bulk critical shear stress is stored if the cohesive sediment formulation is being used. 


\subsection{Floc model}

Maerz et al. (2011) note that there are two approaches for representing particle sizes in models. Distribution-based models use one value (e.g., the average or median) to represent the particle size distribution and sometimes floc density. Distribution-based models are the most common: examples include Winterwerp et al. (2006), Manning and Dyer (2007), and Khelifa and Hill (2006). Van Leussen (1998) and Soulsby et al. (2013) provide reviews. In a numerical model, distribution-based models require advection schemes that allow for spatial and temporal variation in settling velocity. In contrast, size-class-based models represent the particle population by apportioning mass among a discrete number of size classes through semi-empirical descriptions of breakup and aggregation, following the pioneering work of Smoluchowski (1917). Recent examples include Hill and Nowell (1995), Xu et al. (2008), and Verney et al. (2011). One advantage of class-based models it that simpler and more efficient advection schemes designed for constant and uniform settling velocities can be used for each class in turn. The tradeoff is that (many) more size classes are required. Our implementation takes the second approach, and we characterize sediment and floc distributions with several (7-20+) classes, each with fixed characteristics including size, floc density, and settling velocity. This allows us to take advantage of the efficient settling flux algorithms in ROMS.

\subsubsection{Water-column processes}

We implemented the floc model FLOCMOD (Verney et al., 2011) in ROMS to model changes in settling velocity and particle size caused by aggregation and disaggregation. The floc model is a zero-dimensional model that is locally integrated over the baroclinic time step, from initial to final conditions, in every cell of the ROMS model. After the floc populations are updated, the normal settling, advection, and diffusion routines used for tracers (heat, salt, flocs or other sediment, biogeochemical constituents) in ROMS are advanced, with flux boundary conditions at the bed (erosion or deposition) and zero-flux conditions at the surface. FLOCMOD is a population model (Smoluchowski, 1917) based on a finite number of size classes with representative floc diameters $D_{\mathrm{f}}$ $(\mathrm{m})$. The model requires a relationship between floc size and floc density $\rho_{\mathrm{f}}\left(\mathrm{kg} \mathrm{m}^{-3}\right)$ that is related to the primary disaggregated particle diameter $D_{\mathrm{p}}(\mathrm{m})$ and density $\rho_{\mathrm{s}}\left(\mathrm{kg} \mathrm{m}^{-3}\right)$ through a fractal dimension $n_{\mathrm{f}}$ (dimensionless; Kranenburg, 1994) according to

$\rho_{\mathrm{f}}=\rho_{\mathrm{w}}+\left(\rho_{\mathrm{s}}-\rho_{\mathrm{w}}\right)\left(\frac{D_{\mathrm{f}}}{D_{\mathrm{p}}}\right)^{n_{\mathrm{f}}-3}$,

where $\rho_{\mathrm{W}}\left(\mathrm{kg} \mathrm{m}^{-3}\right)$ is the density of the interstitial water in the flocs. The fractal dimension for natural flocs is typically close to 2.1 (Tambo and Watanabe, 1979; Kranenburg, 1994). Floc densities increase as $n_{\mathrm{f}}$ increases, and at $n_{\mathrm{f}}=3$, the flocs are solid particles with $\rho_{\mathrm{f}}=\rho_{\mathrm{s}}$. All cohesive sediment classes are treated as flocs when the floc model is invoked, and the processes of aggregation and disaggregation can shift the mass of suspended sediment from one class to another. The floc model is formulated as a Lagrangian process that takes place within a model cell over a baroclinic model time step while conserving suspended mass in that cell, similar to the way that reaction terms are included in biogeochemical models (for example, Fennel et al., 2006). FLOCMOD simulates aggregation from two-particle collisions caused by either shear or differential settling and disaggregation caused by turbulence shear and/or collisions. The rate of change in the number concentration $N(k)\left(\mathrm{m}^{-3}\right)$ of particles in the $k$ th floc class is controlled by a coupled set of $k$ of differential equations

$$
\begin{aligned}
& \frac{\mathrm{d} N(k)}{\mathrm{d} t}=G_{\mathrm{a}}(k)+G_{\mathrm{bs}}(k)+G_{\mathrm{bc}}(k)-L_{\mathrm{a}}(k) \\
& \quad-L_{\mathrm{bs}}(k)-L_{\mathrm{bc}}(k),
\end{aligned}
$$

where $G$ and $L$ terms $\left(\mathrm{m}^{-3} \mathrm{~s}^{-1}\right)$ represent the gain and loss of mass by the three processes denoted by subscripts: a (aggregation), bs (breakup caused by shear), and bc (breakup caused by collisions). Equation (2) is integrated explicitly using adjustable time steps that may be as long as the baroclinic model time step, but are decreased automatically when necessary to ensure stability and maintain positive particle number concentrations. Particle number concentrations $N(k)$ are related to suspended mass concentrations $C_{\mathrm{m}}(k)\left(\mathrm{kg} \mathrm{m}^{-3}\right)$ via the volume and density of individual flocs. The aggregation and disaggregation terms (Verney et al., 2011) both depend on local rates of turbulence shear, which are calculated from the turbulence submodel in ROMS. Details on these processes are described in the Supplement.

The floc model introduces several parameters (see the Supplement), some of which have been evaluated by Verney et al. (2011). These parameters are specified by the user. The equilibrium floc size depends on the ratio of aggregation to breakup parameters, and the rate of floc formation and destruction depends on their magnitudes (Winterwerp, 1999, 2002). The diameter, settling velocity, density, critical stress for erosion, and critical stress for deposition (described below) are required inputs for each sediment class, both cohesive and non-cohesive (see the Supplement). The present implementation requires a fractal relationship between floc diameter and floc density (Kranenburg, 1994), and we have assumed a Stokes settling velocity. Alternative relationships between diameter and settling velocity, such as a modified Stokes formula (e.g., Winterwerp, 2002; Winterwerp et al., 2002, 2007; Droppo et al., 2005; Khelifa and Hill, 2006), could be used by adjusting input parameters, but alternative relationships between diameter and floc density (Khelifa and Hill, 2006; Nguyen and Chua, 2011) would require changes to the aggregation and disaggregation terms in FLOCMOD. 


\subsubsection{Changes in floc size distribution within the bed}

Changes in the size-class distribution of flocs are expected once they have been incorporated into the seabed, in contrast to non-cohesive particles that retain their properties during cycles of erosion and deposition. For example, it seems unlikely that large, low-density flocs can be buried and later resuspended intact, and limited published observations suggest that material deposited as flocs can be eroded as denser, more angular aggregates (Stone et al., 2008). However, we find little guidance for constraining this process. We therefore have implemented floc evolution in the bed, a simple process that stipulates an equilibrium cohesive sizeclass distribution and an associated relaxation timescale. The time-varying size-class distribution in the bed tends toward the user-specified equilibrium distribution while conserving mass (see the Supplement). If the equilibrium distribution includes more smaller, denser particles and fewer larger, lessdense particles than the depositing flocs, the particle population in the bed will evolve toward smaller, denser particles, changing the amount of material in the classes that is available for resuspension when a cohesive bed is eroded. Example cases presented below demonstrate the effect of this process and the associated timescale on floc distributions both in the bed and in the water column.

\subsection{Bed-water-column exchange}

\subsubsection{Fluxes into the bed - critical shear stress for deposition}

The settling flux of flocs (and all other size classes) into the bed (deposition) over a time step is calculated as $w_{\mathrm{s}, \mathrm{k}} \rho_{k} C_{\mathrm{v}, k} \Delta t\left(\mathrm{~kg} \mathrm{~m}^{-2}\right)$, where $w_{\mathrm{s}, k}\left(\mathrm{~m} \mathrm{~s}^{-1}\right), \rho_{k}\left(\mathrm{~kg} \mathrm{~m}^{-3}\right)$, and $C_{v, k}\left(\mathrm{~m}^{3} \mathrm{~m}^{-3}\right)$ are settling velocities, floc (or particle) densities, and volume concentrations for the $k$ th size class in the bottommost water-column layer, respectively, and $\Delta t$ (s) is the baroclinic time step. An optional critical shear stress for deposition $\left(\tau_{\mathrm{d}}\right.$; Pa; Krone, 1962; Whitehouse et al., 2000; Spearman and Manning, 2008; Mehta, 2014) has been implemented for cohesive sediment. Deposition in our model is zero when the bottom stress $\tau_{\mathrm{b}}(\mathrm{Pa})$ is greater than $\tau_{\mathrm{d}}$. When $\tau_{\mathrm{b}}$ is less than $\tau_{\mathrm{d}}$, deposition increases linearly as $\tau_{\mathrm{b}}$ decreases toward zero, behavior we call linear depositional flux (Whitehouse et al., 2000; see the Supplement). A simpler alternative is to assume a full settling flux when $\tau_{\mathrm{b}}<\tau_{\mathrm{c}}$, which we call constant depositional flux and which we have implemented as an option. According to Whitehouse et al. (2000), $\tau_{\mathrm{d}}$ is typically about half the magnitude of the critical shear stress for erosion $\tau_{\mathrm{b}}$, but is unrelated to that value. Mehta (2014, Eq. 9.83) suggested a relationship between $\tau_{\mathrm{d}}$ for larger particles using $\tau_{\mathrm{d}}$ values for the smallest particles in suspension and the ratio of diameters raised to an exponent that depends on sediment properties (see the Supplement), citing Letter (2009) and Letter and Mehta (2011). The effect of a critical shear stress for deposition is to keep sediment in suspension in the bottom layer. This results in more material transported as suspended sediment and, for flocs, allows aggregation and disaggregation processes to continue.

\subsubsection{Fluxes out of the bed - resuspension}

Resuspension is modeled as an erosional mass flux $E_{\mathrm{s}, i}$ from the top (active) bed layer to the bottommost water-column cell (Ariathurai and Arulanandan, 1978; Warner et al., 2008), where

$E_{\mathrm{s}, i}=E_{0, i}(1-\phi)\left(\tau_{\mathrm{sf}}-\tau_{\mathrm{ce}, i}\right) / \tau_{\mathrm{ce}, i}$

when $\tau_{\mathrm{sf}}>\tau_{\mathrm{ce}}$ and $E_{0}$ is a bed erodibility constant $\left(\mathrm{kg} \mathrm{m}^{-2} \mathrm{~s}^{-1}\right), \phi\left(\mathrm{m}^{3} \mathrm{~m}^{-3}\right)$ is the porosity of the top bed layer, $\tau_{\mathrm{sf}}$ is the skin-friction component of the bottom shear stress $(\mathrm{Pa}), \tau_{\mathrm{ce}}$ is the effective critical shear stress $(\mathrm{Pa})$, and $i$ is an index for each sediment class. The mass of each class eroded over a time step is limited by the amount of that sediment class in the top layer of the bed. The skin-friction component of the bottom shear stress is calculated using a wave current bottom-boundary-layer model (Warner et al., 2008). The effective critical shear stress for non-cohesive sediment depends on grain characteristics, but $\tau_{\text {ce }}$ for cohesive beds is a bulk property of the bed, as discussed below in Sect. 2.5. The effective critical shear stress for mixed beds (i.e., noncohesive grains in a cohesive matrix) varies, as described below in Sect. 2.6.

\subsection{Stratigraphy}

Stratigraphy serves two functions in the model as conditions change and sediment is added to or removed from the bed: (1) representing the mixture of sediment available at the sediment-water interface for use in bed load transport, sediment resuspension, and roughness calculations; and (2) recording the depositional history of sediment. Bookkeeping methods for tracking and recording stratigraphy must conserve sediment mass and must accurately record and preserve age, porosity, and other bulk properties that apply to each layer. Ideally, a layer could be produced for each time step in which deposition occurs, and a layer could be removed when cumulative erosion exceeds layer thickness. In practice, the design of many models is subject to computational constraints that limit resolution to a finite and relatively small number of layers. In ROMS, this number is declared at the beginning of the model run and cannot change. Thus, when deposition requires a new layer or when erosion removes a layer, other layers must be split or merged so that the total number of layers remains unchanged. Where and when this is done determines the fidelity and utility of the modeled stratigraphic record. Some models have used a constant layer thickness (Harris and Wiberg, 2001); others (for example, ECOMSED) define layers as isochrons deposited within a fixed time interval (HydroQual, Inc., 2004). Our approach 
is most similar to that described by Le Hir et al. (2011) in that we allow the mixing of deposited material into the top layer and require a minimum thickness of newly formed layers, merging the bottom layers when a new layer is formed. Likewise, the bottom layer is split when the erosion or thickening of the active layer discussed below reduces the number of layers. The sequence of layer calculations is described in detail in the Supplement.

A key component of the bed model is the active layer (Hirano, 1971), which is the thin (usually millimeter scale) topmost layer of the seabed that participates in exchanges of sediment with the overlying water. During each model time step, deposition and erosion may contribute or remove mass from the active layer. Any stratigraphy in the active layer is lost by instantaneous mixing (Merkel and Klopmann, 2012), but this is consistent with the original concept of Hirano (1971) and the need to represent the spatially averaged surface sediment properties in a grid cell that represents a heterogeneous seabed. The thickness of the active layer in ROMS scales with excess shear stress (Harris and Wiberg, 1997; Warner et al., 2008) and is at least a few median grain diameters thick (Harris and Wiberg, 1997; see the Supplement).

\subsection{Bulk critical shear stress for erosion for cohesive sediment}

An important difference between cohesive and non-cohesive sediment behavior is that the erodibility of cohesive sediment is treated primarily as a bulk property of the bed, whereas the erodibility of non-cohesive sediment is treated as the property of individual sediment classes. The erodibility of cohesive sediment often decreases with depth in the bed, resulting in depth-limited erosion (Type 1 behavior according to Sanford and Maa, 2001). When the cohesive bed module is used, the erodibility of cohesive beds depends on the bulk critical shear stress for erosion $\tau_{\mathrm{cb}}(\mathrm{Pa})$, which is a property of the bed layer, not individual sediment classes, and generally increases with depth in the bed. It also changes with time through swelling and consolidation and, in the uppermost layer, is affected by erosion and deposition. The cohesive bed model tracks these changes by updating profiles of $\tau_{\mathrm{cb}}$ at each grid point during each baroclinic time step.

There is no generally accepted physically based model for determining $\tau_{\mathrm{cb}}$ from bed properties such as particle size, mineralogy, and porosity. We adopted Sanford's (2008) heuristic approach based on the concept that the bulk critical shear stress profile tends toward an equilibrium profile that depends on depth in the seabed (Fig. 1) and must be determined a priori. Erosion chamber measurements (Sanford, 2008; Rinehimer et al., 2008; Dickhudt et al., 2009, 2011; Butman et al., 2014) have been used to define equilibrium bulk critical shear stress profiles $\tau_{\mathrm{cb} \text { eq }}$ in terms of an expo-

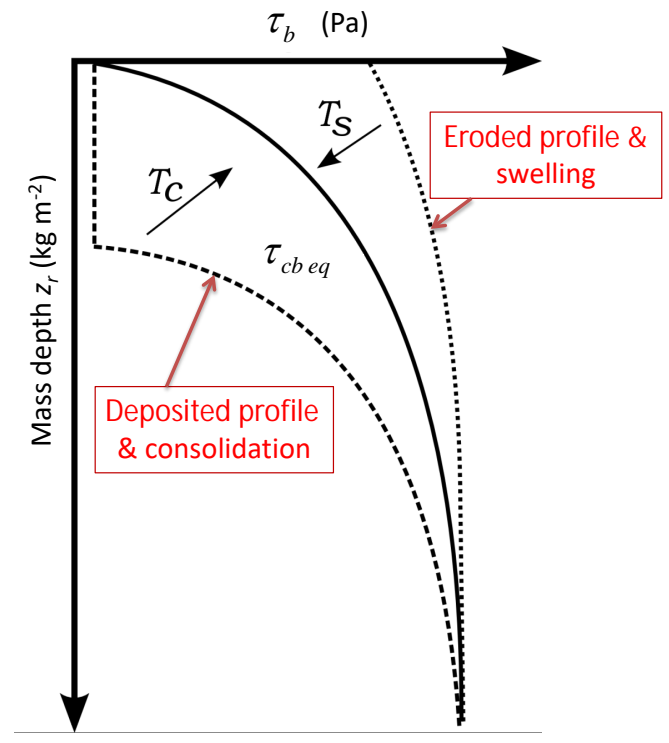

Figure 1. Conceptual diagram of consolidation and swelling (modified from Rinehimer et al., 2008). The equilibrium bulk critical stress for the erosion profile, $\tau_{\mathrm{cbeq}}(z)$, is shown as the solid line. The dotted line represents a critical shear stress profile following sediment erosion. The dashed line is a profile after the deposition of sediment with a low $\tau_{\mathrm{c}}$ at the surface. The arrows indicate consolidation and swelling toward the equilibrium profile with the timescales $T_{\mathrm{c}}$ and $T_{\mathrm{S}}$, respectively.

nential profile defined by a slope and offset.

$\tau_{\text {cb eq }}=a \exp \left[\frac{\ln \left(z_{\mathrm{p}}\right)-\text { offset }}{\text { slope }}\right]$,

where $z_{\rho}\left(\mathrm{kg} \mathrm{m}^{-2}\right)$ is mass depth, the cumulative dry mass of sediment overlying a given depth in the bed. In Eq. (4), offset and slope have units of $\ln \left(\mathrm{kg} \mathrm{m}^{-2}\right)$, and $a=1 \mathrm{~Pa} \mathrm{~kg}^{-1} \mathrm{~m}^{2}$ is a dummy coefficient that produces the correct units of critical shear stress. The mass depth at the bottom of each model layer $k$ is calculated as

$z_{\mathrm{p}}(k)=\sum_{k} \sum_{i} f_{i, k} \rho_{i} \Delta z_{k}$,

where the summations are computed over the $k$ bed layers and $i$ sediment classes, $f_{i}$ (dimensionless) is the fractional amount of sediment class $i, \rho_{i}\left(\mathrm{~kg} \mathrm{~m}^{-3}\right)$ is particle density in class $i$, and $\Delta z_{k}(\mathrm{~m})$ is the thickness of layer $k$. Equation (4) can be written in terms of the power-law fits to erosion chamber measurements presented by Dickhudt (2008) and Rinehimer et al. (2008; see the Supplement). The instantaneous bulk critical shear stress profile is nudged over timescale $T_{\mathrm{c}}$ or $T_{\mathrm{s}}$ (s) toward the equilibrium profile to represent the effects of consolidation or swelling following perturbations caused by erosion or deposition. $T_{\mathrm{c}}$ is the timescale for consolidation and is applied when the instantaneous profile is more erodible than the equilibrium value, while $T_{\mathrm{s}}$ is 
the timescale for swelling and is applied when the instantaneous profile is less erodible than the equilibrium value. The consolidation timescale is usually chosen to be much shorter than the one associated with swelling (Sanford, 2008). New sediment deposited to the surface layer is assigned a bulk critical shear stress that may either be (1) held constant at a low value (Rinehimer et al., 2008) or (2) set at the instantaneous bed shear stress of the flow.

\subsection{Mixed sediment}

Mixed-sediment processes occur when both cohesive and non-cohesive sediment are present and are typically sensitive to the proportion of mud. Beds with very low mud content ( $<3 \%$; Mitchener and Torfs, 1996) behave as non-cohesive sediment: erodibility is determined by particle critical shear stress, which is an intrinsic characteristic of each particle class. Non-cohesive beds may be winnowed and armored by selective erosion of the finer fraction. In contrast, beds with more than 3 to 15-30\% (Mitchener and Torfs, 1996; Panagiotopoulos et al., 1997; van Ledden et al., 2004; Jacobs et al., 2011) mud content behave according to bulk properties that in reality depend on porosity, mineralogy, organic content, age, burial depth, etc., but that in the model are characterized by the bulk critical shear stress for erosion. Our approach to the resuspension of mixed sediment is similar to that suggested by Le Hir et al. (2011) and Mengual et al. (2017). Mixed beds in the model have low to moderate mud content ( 3 to $30 \%$, subject to user specification) and their critical shear stress in the model is a weighted combination of cohesive and non-cohesive values determined by the cohesive-behavior parameter $P_{\mathrm{c}}$, which ranges from 0 (noncohesive) to 1 (cohesive; see the Supplement). Where $P_{\mathrm{c}}=0$, there is no cohesive behavior, and the particle shear stress $\tau_{\mathrm{c}}$ for each sediment class is the effective critical shear stress $\tau_{\mathrm{ce}}$ for that class. Where $P_{\mathrm{c}}=1$, the cohesive sediment algorithm is used, and the effective critical shear stress for each class is the greater of $\tau_{\mathrm{c}}$ and the bulk critical shear stress $\tau_{\mathrm{cb}}$. Between those limits, the effective critical shear stress for each sediment class is

$\tau_{\mathrm{ce}}=\max \left[P_{\mathrm{c}} \tau_{\mathrm{cb}}+\left(1-P_{\mathrm{c}}\right) \tau_{\mathrm{c}}, \tau_{\mathrm{c}}\right]$.

This approach allows fine material (e.g., clay) to be easily resuspended when $P_{\mathrm{c}}$ is low and only a small fraction of mud is present in an otherwise sandy bed, and it limits the flux to the amount available in the active mixed layer. It also allows noncohesive silt or fine sand embedded in an otherwise muddy bed to be resuspended during bulk erosion events when $P_{\mathrm{c}}$ is high, and it provides a simple and smooth transition between these behaviors. The thickness of the active mixed layer is calculated as the thicker of the cohesive and non-cohesive estimates. Figure 2 illustrates mixed-bed behavior as the mud (in this case, clay-sized) fraction $f_{\mathrm{c}}$ increases for a constant bottom stress of $0.12 \mathrm{~Pa}$. At low $f_{\mathrm{c}}, P_{\mathrm{c}}$ is zero (Fig. 2a), and clay and silt are easily eroded (high relative flux rates out of the bed; Fig. 2c) because the particle critical shear stress for non-cohesive behavior of these fine particles is low (Fig. 2b). The relative flux rates in Fig. $2 b$ are normalized by the fractional amount of each class and the erosion rate coefficient; the actual erosional fluxes for clay content would be low at $P_{\mathrm{c}}=0$ because of the low clay content in the bed. As $f_{\mathrm{c}}$ increases and the bed becomes more cohesive, relative erosion flux rates decline. When $f_{\mathrm{c}}$ exceeds a critical value $(0.2$ in the example shown in Fig. 2), the bed is completely cohesive and erosion fluxes are determined by bulk critical shear stress for erosion of cohesive sediment $\tau_{\mathrm{cb}}$.

Non-cohesive sediment classes are subject to bed load transport when the bottom stress exceeds both the bulk critical shear stress of the top (active) layer and the particle critical shear stress for that class. In these cases, the transport rate equations still calculate bed load transport based on excess shear stress associated with the non-cohesive particle critical shear stress, as described in Warner et al. (2008). Cohesive classes are not subject to bed load transport; if the bulk critical shear stress of the bed is exceeded, we assume they will go directly into suspension.

\subsection{Bed mixing}

The mixing of bed properties in sediment can be caused by benthic fauna (ingestion, defecation, or motion such as burrowing) or the circulation of porewater and tends to smooth gradients in stratigraphy and move material vertically in sediment. The model (e.g., Boudreau, 1997) assumes that mixing is a one-dimensional vertical diffusive process and neglects nonlocal and lateral mixing processes:

$\frac{\partial C_{\mathrm{v}}}{\partial t}=\frac{\partial}{\partial z}\left(D_{\mathrm{b}} \frac{\partial C_{\mathrm{v}}}{\partial z}\right)$,

where $C_{\mathrm{v}}$ is the volume concentration of a conservative property (e.g., fractional concentration of sediment classes or porosity), $D_{\mathrm{b}}$ is a (bio)diffusion coefficient $\left(\mathrm{m}^{2} \mathrm{~s}^{-1}\right)$ that may vary with depth in the bed (see below), and $z(\mathrm{~m})$ is depth in the bed (zero at the sediment-water interface, positive downward). We have discretized Eq. (7) with varying bed thicknesses and solve it at each baroclinic time step using an implicit method that is stable and accurate (see the Supplement).

Biodiffusivity is generally expected to decrease with depth in the sediment (Swift et al., 1994, 1996), but is often assumed to be uniform near the sediment-water interface. The typical depth of uniform mixing, based on worldwide estimates using radionuclide profiles from cores, is $9.8 \pm$ $4.5 \mathrm{~cm}$ (Boudreau, 1994). Rates of biodiffusion estimated from profiles of excess ${ }^{234} \mathrm{Th}$ on a muddy mid-shelf deposit off Palos Verdes (California, USA) varied from $\sim 2$ to $\sim 80 \mathrm{~cm}^{2} \mathrm{y}^{-1}$ (Wheatcroft and Martin, 1996; Sherwood et al., 2002) and values from the literature range from 0.01 to $100 \mathrm{~cm}^{2} \mathrm{y}^{-1}$ (Boudreau, 1997; Lecroart et al., 2010). The depth-dependent biodiffusion rate profile in the model must 

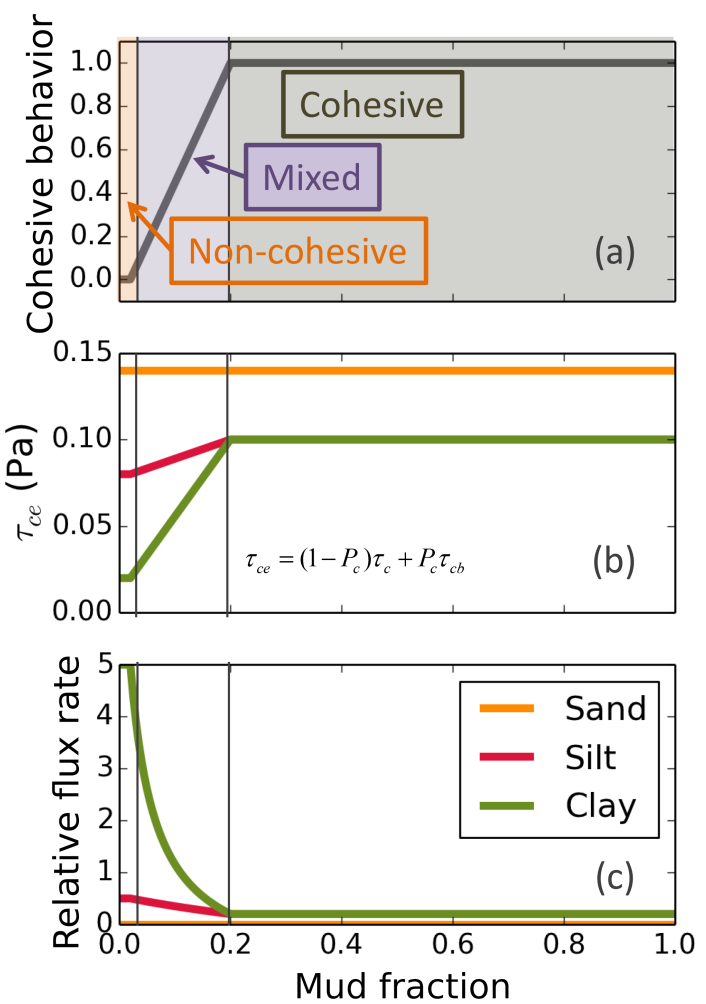

Figure 2. Summary of mixed-bed behavior with increasing mud fraction $f_{\mathrm{c}}$ (the combined mass fraction of material in cohesive classes). (a) Cohesive behavior parameter $P_{\mathrm{c}}$ as a function of $f_{\mathrm{c}}$. (b) Effective critical shear stress $\tau_{\text {ce }}$ for size classes in which the bulk critical shear stress of the bed $\tau_{\mathrm{cb}}=0.1 \mathrm{~Pa}$. (c) Relative flux (normalized excess shear stress) from the bed when bed stresses are $\sim \tau_{\mathrm{b}}=0.12 \mathrm{~Pa}$ (greater than $\tau_{\mathrm{c}}$ for clay and silt primary particles, but less than $\tau_{\mathrm{c}}$ for sand).

be specified for each horizontal grid cell using a generalized shape described in the Supplement.

Representation of seabed properties, i.e., the stratigraphy, has been modified slightly from the framework presented in Warner et al. (2008). The revised bed model gives the user latitude to control the resolution of the stratigraphy through the choice of new layer thickness and the number of bed layers and avoids the mixing described by Merkel and K1opmann (2012). The bookkeeping for bed layers is detailed in the Supplement. The main differences from previous versions of the model (Warner et al., 2008) are the treatments of the second layer (immediately below the active layer) and the bottom layer. During deposition, the new algorithm prevents the second layer from becoming thicker than a user-specified value, which results in thinner layers that can record changes in sediment composition inherited from the active layer as materials settle. During erosion, the new algorithm splits off only a small portion of the bottom layer to create a new layer. This limits the influence of the initial stratigraphy specified for the bottom layer and confines blurring of the stratigraphic record to the bottommost layers. Our tests indicate the new approach provides a more informative record of stratigraphic changes. Moriarty et al. (2017) used a similar approach to bed stratigraphy to preserve spatial gradients in sediment biogeochemistry.

\section{Demonstration cases}

The following cases demonstrate the cohesive sediment processes included in ROMS, explore model sensitivity to parameters, and provide candidates for inter-model comparisons.

\subsection{Floc model}

Tests using zero-dimensional and one-dimensional vertical implementations of ROMS were conducted to verify that the floc model was implemented correctly and to gain some insight into model behavior under typical coastal conditions.

\subsubsection{Comparison with laboratory experiments}

Verney et al. (2011) compared results from FLOCMOD with a laboratory experiment of tidal cycle variation in shear rate $G$. We performed the same simulations in ROMS by initializing with the same floc model parameters. The model was run with 15 cohesive classes (instead of the 100 classes in the reference FLOCMOD experiment). Settling velocities were set to zero, and the turbulent shear parameter $G(t)$ was specified, ranging from $G=0 \mathrm{~s}^{-1}$ at slack tide to $G=12 \mathrm{~s}^{-1}$ at peak flow. Periodic lateral boundary conditions were used, effectively creating a zero-dimensional simulation in which the only active process was floc response to the changing turbulent shear. The class sizes were log-spaced between 4 and $1500 \mu \mathrm{m}$ with floc densities derived from Eq. (1) using $n_{\mathrm{f}}=1.9$. The suspended sediment concentration was constant at $0.093 \mathrm{~kg} \mathrm{~m}^{-3}$, and it was initially all in the $120 \mu \mathrm{m}$ class. Our results (Fig. 3a) matched the cycles of floc diameter variation caused by aggregation (low $G$ ) and breakup (high $G$ ) shown in Fig. 7 of Verney et al. (2011), with a $24 \mu \mathrm{m}$ root mean square (RMS) difference from observations in mass-weighted mean diameter. As in the Verney et al. (2011) simulation, our model did not reproduce the dip in mean grain diameter at $\sim 400 \mathrm{~min}$, which may have been caused by the settling of the larger flocs in the laboratory experiment.

We also compared our ROMS FLOCMOD implementation with laboratory experiments of the growth and breakup of flocs performed by Keyvani and Strom (2014), who used a constant sediment concentration of $0.05 \mathrm{~kg} \mathrm{~m}^{-3}$ and applied cycles of $G=15 \mathrm{~s}^{-1}$ that caused floc growth followed by long periods $(15 \mathrm{~h})$ of very strong turbulent shear rates $\left(G=400 \mathrm{~s}^{-1}\right)$ that caused disaggregation. We simulated the first cycle of floc formation using the size classes, fractal dimension, and concentrations provided by Keyvani and Strom (2014), but varied the aggregation parameter $\alpha$ and 

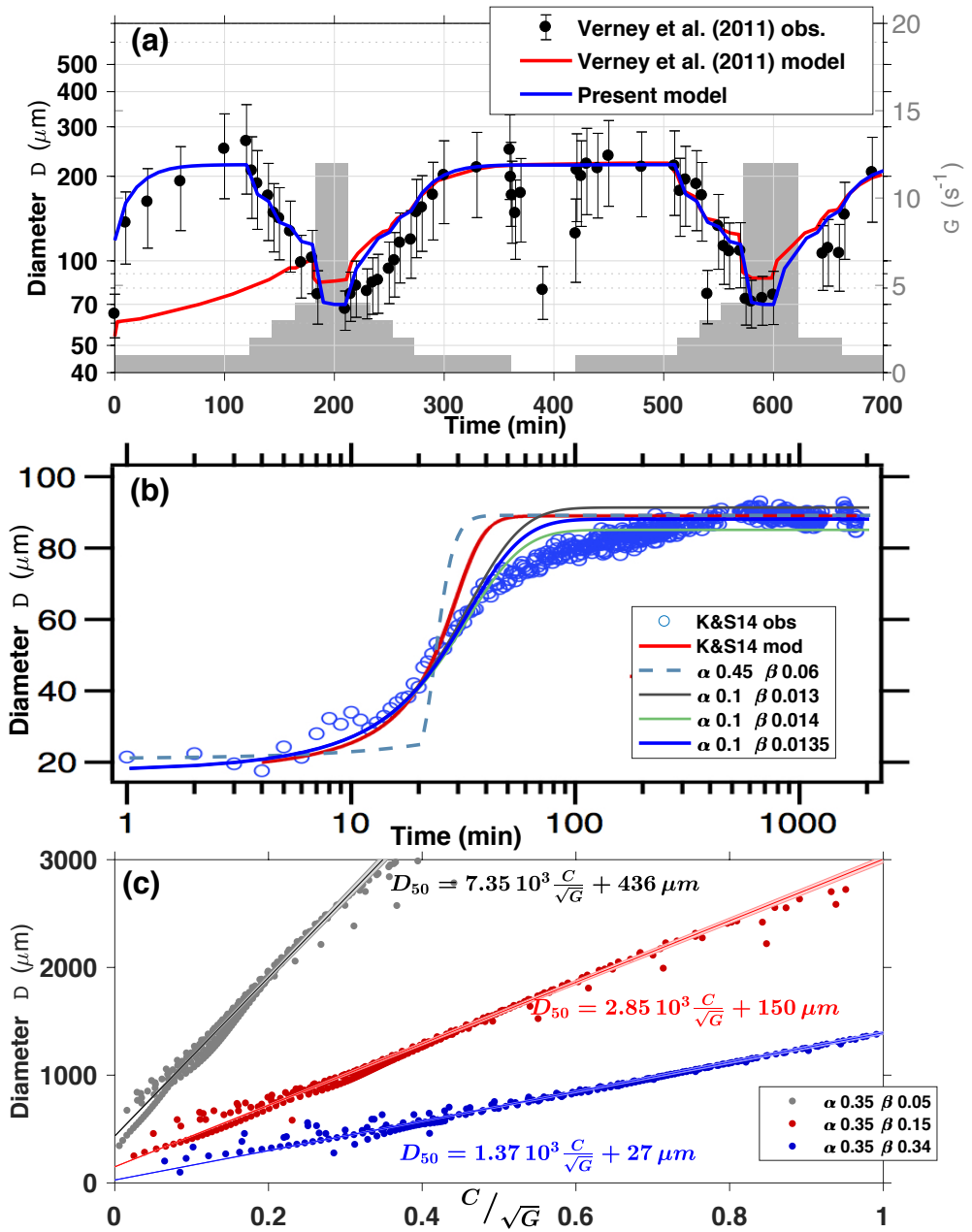

Figure 3. Comparison of ROMS implementation of FLOCMOD with laboratory and theoretical results. (a) Laboratory response of floc size to simulated fluctuations in shear rate $G$ (gray shading) showing observed area-weighted mean floc diameter $D$ (black dots with $+/ 1$ standard deviation bars), model results presented in Verney et al. (2011; red line), and ROMS FLOCMOD simulation (blue line). (b) Laboratory response of floc size to rapid increase in shear rate from $G=0$ to $G=15 \mathrm{~s}^{-1}$ showing sizes measured by Keyvani and Strom (2014; K\&S14; blue circles), K\&S14 model results (red line), and ROMS FLOCMOD results for various combinations of aggregation and breakup parameters (dashed and colored lines). (c) Equilibrium diameters produced by steady ROMS FLOCMOD simulations with a range of concentrations, shear rates, and aggregation and breakup parameters (dots). These fall along lines with slopes determined by the ratio of aggregation and breakup parameters, according to theory (Winterwerp, 1998).

the breakup parameter $\beta$ that determine the final equilibrium diameter. Our model results with $\alpha=0.1$ and $\beta=0.0135$ (Fig. 3b) reproduced the observations with higher skill than the simple model used in their study. The same final diameter was obtained with $\alpha=0.45$ and $\beta=0.06$, but the equilibrium was attained more quickly than observed.

These comparisons with laboratory results indicated that our implementation of FLOCMOD in ROMS was correct and demonstrated that the model has useful skill in representing floc dynamics.

\subsubsection{Comparison to equilibrium floc size}

Simulations were conducted to further evaluate the ROMS implementation of FLOCMOD by comparing modeled equilibrium floc sizes to equilibrium floc sizes predicted by Winterwerp et al. (2006). He argued that, in steady conditions, equilibrium floc sizes are determined by the fractal dimension $n_{\mathrm{f}}$, the ratio of aggregation rates and breakup rates, concentration $C\left(\mathrm{~kg} \mathrm{~m}^{-3}\right)$, and turbulence shear rate $G\left(\mathrm{~s}^{-1}\right)$. The equilibrium median floc size $D_{50}(\mathrm{~m})$ is given by

$D_{50}=D_{\mathrm{p}}+\frac{k_{\mathrm{A}}}{k_{\mathrm{B}}} \frac{C}{\sqrt{G}}$, 
where $k_{\mathrm{A}}$ and $k_{\mathrm{B}}$ are aggregation and breakup coefficients, respectively (Winterwerp, 1998). The units of $k_{\mathrm{A}}$ and $k_{\mathrm{B}}$ depend on fractal dimensions, but the ratio has units of $\mathrm{m}^{4} \mathrm{~kg}^{-1} \mathrm{~s}^{-1 / 2}$. We compared our FLOCMOD results with this theoretical relationship by running cases with steady conditions, $n_{\mathrm{f}}=2$, for a range of concentrations $(C=0.1$ to $\left.10 \mathrm{~kg} \mathrm{~m}^{-3}\right)$, a range of shear rates $\left(G=0.025\right.$ to $\left.100 \mathrm{~s}^{-1}\right)$, and several combinations of aggregation and breakup parameters $\alpha$ and $\beta$. The results show that equilibrium floc size increases with concentration and decreases with turbulence shear rate, as expected (Fig. 3c). Equilibrium diameter is strongly controlled by concentration, and turbulence is more effective at reducing average diameter at lower concentrations. The slope of the relationship between the equilibrium diameter and $C / \sqrt{G}$ varies with the ratio of aggregation to breakup. Winterwerp (1998) suggested a slope of about $4 \times 10^{3} \mathrm{~m}^{4} \mathrm{~kg}^{-1} \mathrm{~s}^{-1 / 2}$. Figure $3 \mathrm{c}$ demonstrates that a range of slopes can be obtained by varying the ratio $\alpha / \beta$. The model reproduced the linear response predicted by Winterwerp (1998) except near the largest sizes, where our upper limit in floc-class size $(5000 \mu \mathrm{m})$ distorted the statistics. Although not shown in Fig. 3c, the floc populations evolved at different rates depending on $\alpha$ and $\beta$, as indicated in Fig. 3b.

\subsubsection{Evolution to steady state}

Steady, uniform flow is a conceptually simple model test that demonstrates the hydrodynamics linking vertical profiles of flow, the evolution of the turbulent boundary layer, and bottom drag. The addition of floc dynamics creates a complicated and instructive test case. The model setup was a fully three-dimensional implementation with advection, diffusion, and settling of the dynamically changing floc population. The vertical grid included 40 cells, but the horizontal aspect of the grid was small (five cells, which is just enough to accommodate the templates of the finite-difference formulations) and included lateral periodic boundary conditions so that anything advected out of the domain reentered on the upstream side. This simulation, forced by a constant sea-surface slope, is similar to the steady flow test examined by Winterwerp (2002, Sect. 4.8.1) and produces a linear Reynolds stress profile increasing from zero at the surface to $\tau_{\mathrm{b}}=-\rho_{\mathrm{w}} g h(\mathrm{~d} s / \mathrm{d} x)$ at the seabed, where $\tau_{\mathrm{b}}(\mathrm{Pa})$ is bottom shear stress, $g\left(\mathrm{~m} \mathrm{~s}^{-2}\right)$ is gravitational acceleration, $h(\mathrm{~m})$ is water depth, and $\mathrm{d} s / \mathrm{d} x\left(\mathrm{~m} \mathrm{~m}^{-1}\right)$ is sea-surface slope. The flow develops a logarithmic velocity profile $u=$ $\left(u_{*} / \kappa\right) \ln \left(z / z_{0}\right)$, where $u\left(\mathrm{~m} \mathrm{~s}^{-1}\right)$ is velocity in the $x$ direction, $u_{*}=\sqrt{\left(\tau_{\mathrm{b}} / \rho_{\mathrm{w}}\right)}$ is shear velocity $\left(\mathrm{m} \mathrm{s}^{-1}\right), \kappa=0.41$ (dimensionless) is von Kármán's constant, $z$ (m) is elevation above the bed, and $z_{0}(\mathrm{~m})$ is the bottom roughness length. The final flow velocity near the surface is about $0.6 \mathrm{~m} \mathrm{~s}^{-1}$. When non-cohesive sediment is added (and erosion and deposition are set to zero), the suspended sediment concentrations for each size class evolve into Rouse-like profiles in which, at each elevation, downward settling is balanced by upward diffusion. The addition of floc dynamics complicates the situation because aggregation creates larger flocs with higher settling velocities. The larger flocs tend to settle into regions of higher shear and higher concentration, where the higher shear tends to break them into smaller flocs but the higher concentrations enhance aggregation. The size distribution, settling velocity, concentration, shear, and turbulent diffusion evolve to a steady state under a dynamic balance. The resulting profiles of concentration and mass-weighted average size and settling velocity are sensitive to both floc model parameters and modeled physical conditions (water depth, bottom stress, turbulence model, total sediment in suspension).

We demonstrate this process using 22 floc classes with logarithmically spaced diameters ranging from 4 to $5000 \mu \mathrm{m}$ (Fig. 4). The initial vertical concentration profile was uniform at $0.2 \mathrm{~kg} \mathrm{~m}^{-3}$, all in the $8 \mu \mathrm{m}$ class. The model started from rest, and the initial response was slow particle settling in the nearly inviscid flow: concentrations, floc sizes, and settling velocities all decreased near the surface (Fig. 4a, b, and c). As the flow accelerated in the first $2 \mathrm{~h}$, turbulence generated by shear at the bottom began to mix upward in the water column, diffusing settled material higher and facilitating collisions and aggregation among flocs. Between hours 3 and 4 , settling was enhanced by these newly formed larger flocs, as is apparent in increases in average diameter and settling velocities and reduced concentrations near the surface. Equilibrium was nearly established by about hour 5 . At the end of the model run, the total concentration profile decreased exponentially with elevation (Fig. $4 \mathrm{~d}$ and g), but average size and settling velocities both decreased markedly in the bottom meter (Fig. 4e and f), reflecting shear disaggregation that leads to increases in smaller flocs near the bottom (Fig. 4g).

The timescales to achieve equilibrium in this simulation are comparable to tidal timescales, suggesting equilibrium is unlikely in the real world where forcing is time dependent and bottom conditions are spatially variable. The final condition is sensitive to flow forcing, initial concentrations, and floc parameters. For example, when concentrations are higher or when the disaggregation parameter is increased (making the flocs more fragile), bottom-generated shear causes disaggregation higher into the water column, and mid-depth maxima in diameter and settling velocity evolve. This steady flow simulation is useful as both a standard test case and a reminder of the complexity of floc processes, even when the hydrodynamics are relatively simple.

\subsubsection{Settling fluxes}

Interaction with the bed influences the evolution of the floc population in the water column by providing sources or sinks in various size classes. We have experimented with several sediment flux conditions from the water column to the seabed, including settling fluxes, zero fluxes, and fluxes modulated by threshold stresses for deposition. Set- 

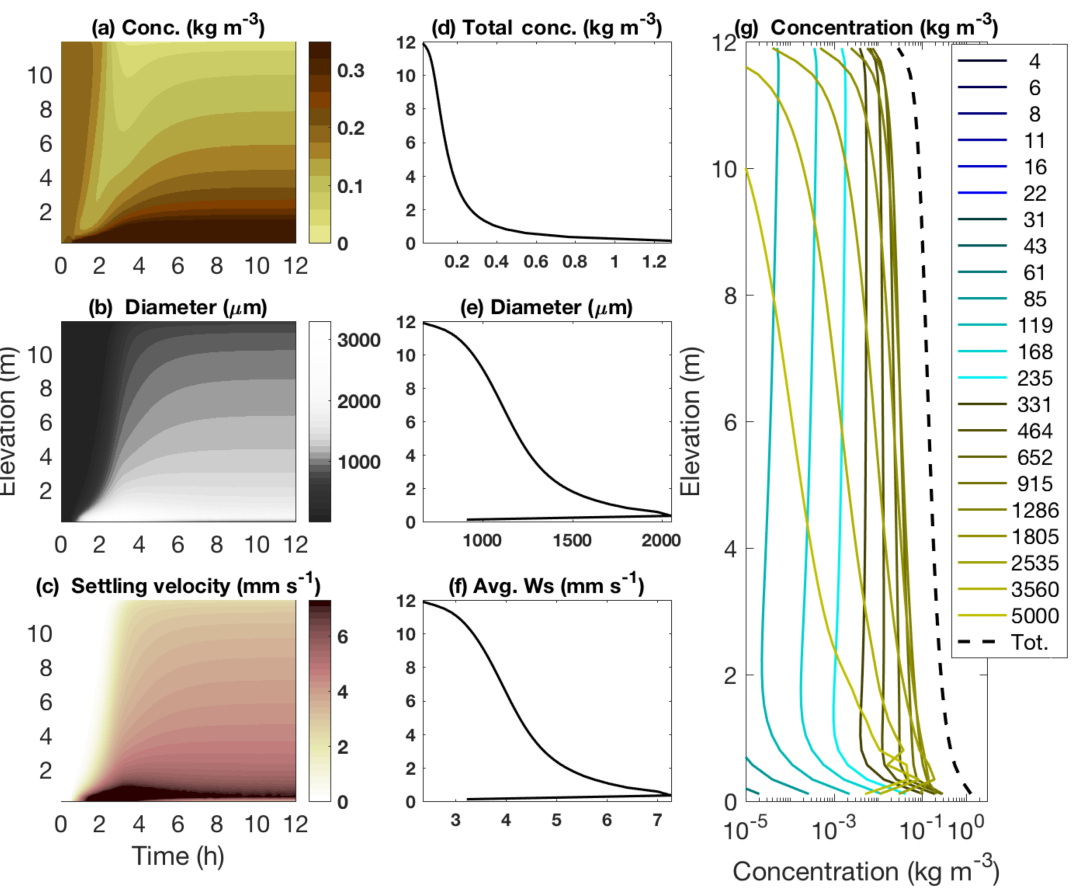

Figure 4. Simulation of steady open-channel flow initialized with a vertically uniform concentration of $0.2 \mathrm{~kg} \mathrm{~m}^{-3}$ in the $8 \mu \mathrm{m}$ class. Temporal evolution of profiles of (a) mass concentration, (b) mass-weighted diameter, and (c) mass-weighted settling velocity. Final profiles of (d) concentration, (e) diameter, and (f) settling velocity, and (g) final concentration profiles for each class size (colored lines) and the sum of all classes (dashed line).

tling fluxes calculated as $w_{k} \rho_{k} C_{k} \Delta t$ summed over each class $k$ is the default method used for non-cohesive sediment. Zero-flux boundary conditions essentially treat the bottom water-column cell as a fluff layer, allowing flocs to accumulate by settling or to mix out by diffusion. Floc dynamics continue to operate in this layer, so the size distributions change with concentration and stress. Settling fluxes modulated by stress thresholds for deposition allow flocs to deposit only under relatively quiescent conditions. The model framework provides a variety of choices described in the Supplement, each with implications that must be assessed in the context of the problem at hand. As expected, the conditions that reduced settling into the bed resulted in higher sediment concentrations in the bottommost water-column layer and allowed for floc breakup by the enhanced near-bottom turbulence.

\subsubsection{Model sensitivity}

A wide range of model runs (not presented here) have provided us with a qualitative sense of model performance. Model results respond as expected to physical parameters, such as mean concentration and shear rate (discussed above), as well as primary particle size and fractal dimension. Model results are also sensitive to model configuration, including the number of size classes, the size of vertical grid spacing, and the time step used. Our experience so far confirms that of Verney et al. (2011): a truncated distribution of about seven size classes provides qualitatively useful results, but the choice of size range and size distribution may change the results. The sensitivity to vertical grid resolution is particularly important in the bottommost layer, which has the highest concentrations and highest shear rates. Finer grid spacing near the bottom results in layers with higher shear and higher sediment concentrations, which cause local changes in the equilibrium floc sizes. Model time steps in our floc model tests are short, ranging from 10 to (more typically) $1 \mathrm{~s}$. The adaptive sub-steps for aggregation and disaggregation were limited to a minimum of $0.5 \mathrm{~s}$. At high concentrations $\left(>0.2 \mathrm{~kg} \mathrm{~m}^{-3}\right)$ and high shear rates, the results sometimes showed numerical instability, probably related to the explicit solution of Eq. (2). Replacement of the solver for these equations with a faster and more robust method in the future should improve model stability.

\subsection{Resuspension}

Three cases are presented here to demonstrate the evolution of stratigraphy caused by resuspension and subsequent settling of sediment during time-dependent bottom shear stress events. They contrast model calculations using the non-cohesive and mixed-bed routines and highlight the role of biodiffusion. These were one-dimensional (vertical) cases represented with small $(\sim 5 \times 6$ horizontal $\times 20$ vertical cells), three-dimensional domains with flat bottoms and pe- 

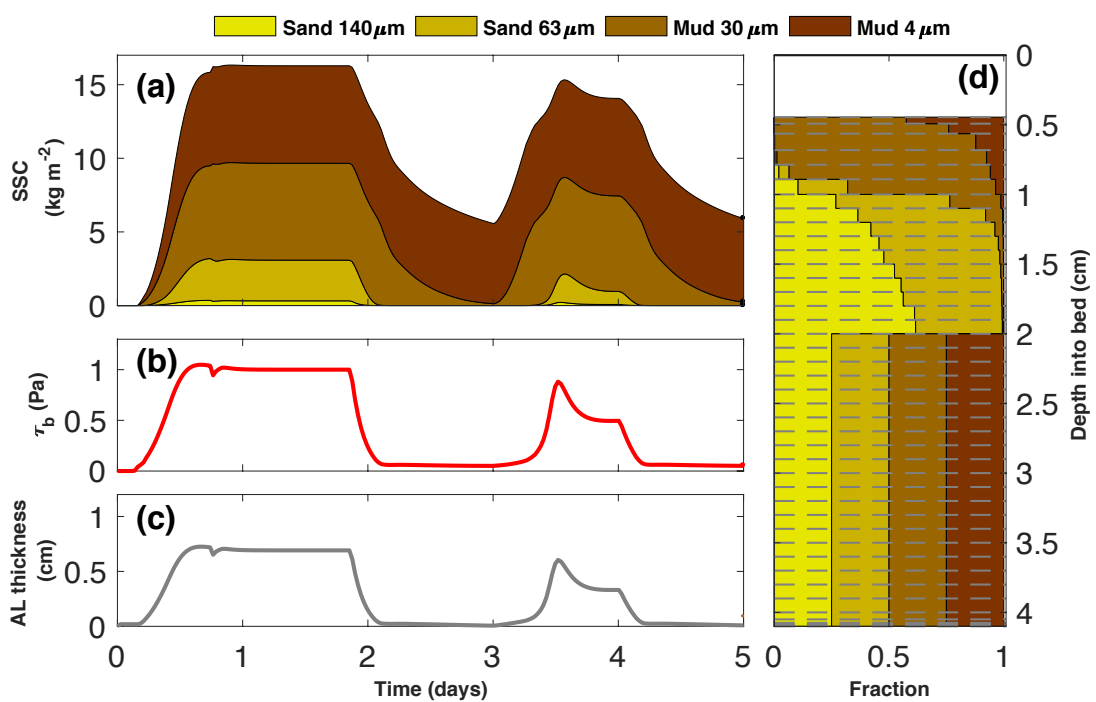

Figure 5. Summary of the double resuspension experiment with non-cohesive sediment over 5 days. The model setup included 41 bed layers, a minimum new layer thickness of $1 \mathrm{~mm}$, and four non-cohesive classes. The top horizontal panel (a) shows the time evolution of the mass of sediment in suspension colored by size class. The middle horizontal panel (b) is the time series of bottom stress, and the bottom horizontal panel (c) shows the corresponding time series of active-layer thickness. The right panel (d) depicts the final stratigraphy relative to the initial bed level at zero and shows the fraction of each sediment class in each bed layer.

riodic lateral boundary conditions on all sides. They were forced with time-varying surface wind stress that generated time-dependent horizontal velocities and bottom stress, initialized with zero velocity and zero suspended sediment concentration, and did not include floc dynamics in the water column.

\subsubsection{Non-cohesive bed simulation}

A non-cohesive bed simulation with a water depth of $20 \mathrm{~m}$ and periodic boundary conditions was used to demonstrate the generation and preservation of sand and silt stratigraphy during a resuspension and settling event (Fig. 5). The model was forced with two stress events $\sim 1.5$ days apart and lasting 1.5 and 1 days, respectively. Four sediment classes representing particles with nominal diameters of $4,30,62.5$, and $140 \mu \mathrm{m}$, particle critical shear stresses of $0.05,0.05,0.1$, and $0.1 \mathrm{~Pa}$, and settling velocities of $0.1,0.6,2$, and $8 \mathrm{~mm} \mathrm{~s}^{-1}$ were used. Although the diameters of the first two sediment classes corresponded to mud, all sediment classes in this experiment were treated as non-cohesive material. The initial sediment bed contained 41 layers, each $1 \mathrm{~mm}$ thick and each holding equal fractions $(25 \%)$ of the four sediment classes. New sediment layers were constrained to be no more than $1 \mathrm{~mm}$ thick.

The first, larger stress event (maximum $=1$ Pa; Fig. 5b) eroded $1.2 \mathrm{~cm}$ of bed and expanded the active layer to a thickness of $0.8 \mathrm{~cm}$, so the bed was disturbed to a depth of $2 \mathrm{~cm}$. Expansion of the active layer homogenized enough layers to provide $0.8 \mathrm{~cm}$ of sediment, making more fine sediment available for resuspension. The finer fractions dominated the suspended sediment in the water column, which contained only a small fraction of the coarsest sand (Fig. 5a). When the stress subsided, coarser sediment deposited first, while finer material remained suspended, producing thin layers of graded bedding above the $2 \mathrm{~cm}$ limit of initial disturbance (Fig. 5d).

The second stress pulse eroded the bed down to $1 \mathrm{~cm}$ but only resuspended minimal amounts of the $140 \mu \mathrm{m}$ sand. Deposition resumed after the second pulse subsided, and at the end of the simulation, some mud remained in the water column (Fig. 5a), leaving the bed with net erosion of $5 \mathrm{~mm}$ (Fig. 5d). The finest material $(4 \mu \mathrm{m})$ remained mostly in suspension after 5 days. The final thickness of the bottom five layers was smaller than their initial value $(1 \mathrm{~mm})$ because to maintain a constant number of bed layers, the deepest layer was split each time a surface layer was formed during deposition. The two stress pulses affected sediment texture down to $2 \mathrm{~cm}$. Above this level, almost all of the finest class was winnowed and remained mostly in suspension, while the other classes settled to the bed so that the upper bed layers developed a fining-upward storm layer. The bottom portion of the storm layer (1-2 cm of depth) was a lag layer comprised of the two coarsest classes, both because these resisted erosion and because the sand that did erode settled to the bed quickly when shear stress decreased.

\subsubsection{Mixed-bed simulation}

This case examined the stratigraphic consequences of cohesive behavior resulting from a single bottom-stress event (Fig. 6). The model configuration was similar to the previ- 
ous example. The same sediment classes were used, but the two finest ( 4 and $30 \mu \mathrm{m})$ were treated as cohesive mud, while the other two remained non-cohesive (sand). The fraction of cohesive sediment $\left(f_{\mathrm{c}}=0.5\right)$ exceeded the chosen noncohesive threshold ( $f_{\text {nc threshold }}=0.2$ ), so the bed behaved as if it were completely cohesive. The cohesive formulation required the initialization of an equilibrium bulk critical stress profile for erosion. We chose parameters within the range of sensitivities studied by Rinehimer et al. (2008) and specified an equilibrium profile with a slope of $2 \ln \left(\mathrm{kg} \mathrm{m}^{-2}\right)$ and an offset of $3.4 \ln \left(\mathrm{kg} \mathrm{m}^{-2}\right)$, with a minimum value of $0.03 \mathrm{~Pa}$ and a maximum of $1.5 \mathrm{~Pa}$ (dashed magenta line in Fig. 6b) and initialized the model with this profile (solid purple line in Fig. 6b). The timescale for consolidation was set to $T_{\mathrm{c}}=8 \mathrm{~h}$. The swelling timescale was chosen to be 100 times longer than consolidation ( $T_{\mathrm{S}}=33$ days). A time series of bed stress was imposed (Fig. 6a), and the bed responded initially by eroding. As the imposed stress waned starting at day 37, sediment settled to the bed, causing deposition. The initial rapid increase in bottom stress during the first 0.7 days (Fig. 6a) exceeded the critical stress of the bed to a depth of $2.4 \mathrm{~cm}$ (red line in Fig. 6c), causing resuspension and erosion of the top $5 \mathrm{~mm}$ of the bed. In this case, the amount of material eroded was limited by the erosion rate coefficient. The equilibrium critical stress profile, which has a static shape, shifted down with the sediment-water interface (compare dashed magenta line in Fig. 6b, c). After the initial erosion, the instantaneous critical stress profile tended toward the equilibrium critical stress profile over the slow swelling timescale of 33 days, rendering the bed progressively more erodible (compare Fig. 6c, d). The process of swelling, while slow, rendered the bed more erodible, and an additional $2-3 \mathrm{~mm}$ of sediment was removed by day 32 . By day 38 , the stress had waned and $4 \mathrm{~mm}$ of sediment had redeposited (Fig. 6d). The equilibrium critical stress profile had shifted upward with the bed surface, causing the instantaneous critical stress to increase over the short compaction timescale. The final instantaneous critical shear stress profile (Fig. 6e) had almost reached the long-term equilibrium everywhere except in the most recent deposits. This case exemplifies the sequence of depth-limited erosion, deposition, and compaction that characterizes the response of mixed and cohesive sediment in the model.

\subsubsection{Biodiffusion simulations}

We validated the numerical performance of the biodiffusion algorithms using two analytical test cases with a realistic range of parameters. The implicit numerical solution is unconditionally stable and conserves mass to within $10^{-8} \%$, but the accuracy depends on time step, gradients in biodiffusivity, and bed thickness. Typical RMS differences in the fractional amount of sediment in a particular class between the numerical solutions and the analytical solutions ranged from $10^{-2}$ to $10^{-6}$. We found that, for modeled beds $5 \mathrm{~m}$

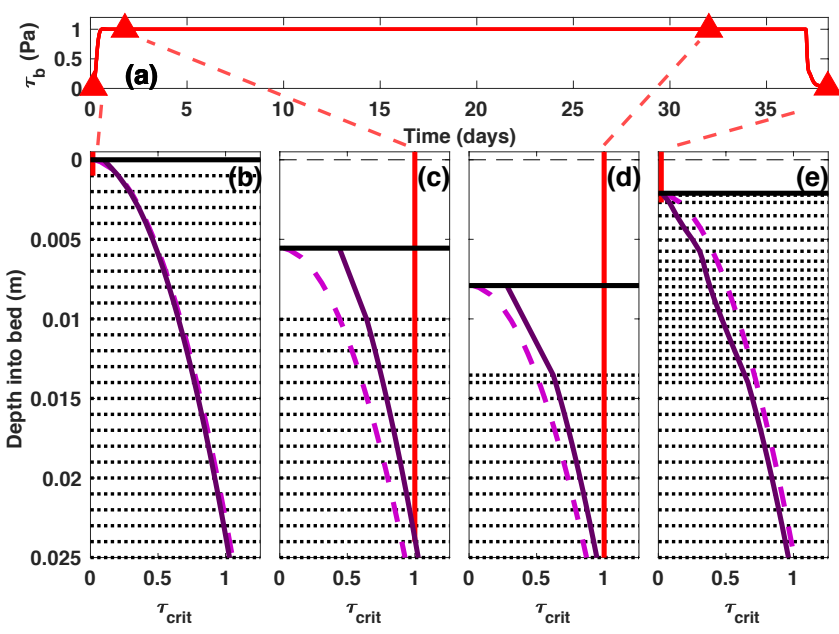

Figure 6. Time series of bottom stress (a) and profiles of critical shear stress for erosion during four distinct conditions: (b) initial bed condition; (c) eroded bed (after 1.3 days with $\tau_{\mathrm{b}}=1.0 \mathrm{~Pa}$ ); (d) after slow but continuous erosion and reduced bulk critical stress profile due to swelling after 30 days more with $\tau_{\mathrm{b}}=1.0 \mathrm{~Pa}$; and (e) rapid deposition after a day of low stress with $\tau_{\mathrm{b}}=0.1 \mathrm{~Pa}$. In the lower panels, the solid red line is the magnitude of the bottom stress $\left(\tau_{\mathrm{b}}\right)$, the dashed magenta line is the equilibrium profile of bulk critical stress for erosion $\tau_{\mathrm{cb}}(z)$, and the solid purple line is the instantaneous profile of bulk critical stress for erosion. The solid black line is the instantaneous position of the top of the bed at each time, with the initial bed elevation starting at zero.

thick, solutions improved as layer thickness decreased from 50 to $5 \mathrm{~cm}$, but beyond that, higher resolution did not substantially improve the solution. Even in the worst case in which the numerical solution was off by $1 \%$, it was much more precise than our estimates of biodiffusivity coefficients.

Four cases are presented to demonstrate bed mixing (Fig. 7). The first two used configurations similar to the non-cohesive (Figs. 5, 7a) and mixed-bed simulations (Figs. 6, 7b). The second two were identical to the mixedbed case except that biodiffusive mixing was enabled. The biodiffusivity profile used was similar to that proposed for the mid-shelf deposit offshore of Palos Verdes, CA (Sherwood et al., 2002) that had a constant diffusivity $D_{\text {bs }}$ from the sediment-water interface down to $2 \mathrm{~mm}$, an exponential decrease between 2 and $8 \mathrm{~mm}$, and a linear decrease to zero at $1 \mathrm{~cm}$ of depth. These two cases differed in their biodiffusion coefficients: (a) the first used relatively large biodiffusion coefficients $\left(D_{\mathrm{bs}}=10^{-5} \mathrm{~m}^{2} \mathrm{~s}^{-1}\right)$ and (b) the second used smaller values $\left(D_{\mathrm{bs}}=10^{-10} \mathrm{~m}^{2} \mathrm{~s}^{-1}\right)$.

The resulting stratigraphy after the 5-day simulation (Fig. 7) indicates that mixing in the case with large biodiffusivity (Fig. 7c) tended to smooth all gradients rapidly and only during depositional conditions was the vertical structure of grain size fractions preserved. Some sediment remained in suspension in all four cases, which was reflected in the final bed elevation. The resulting top $1 \mathrm{~cm}$ of the bed was always 

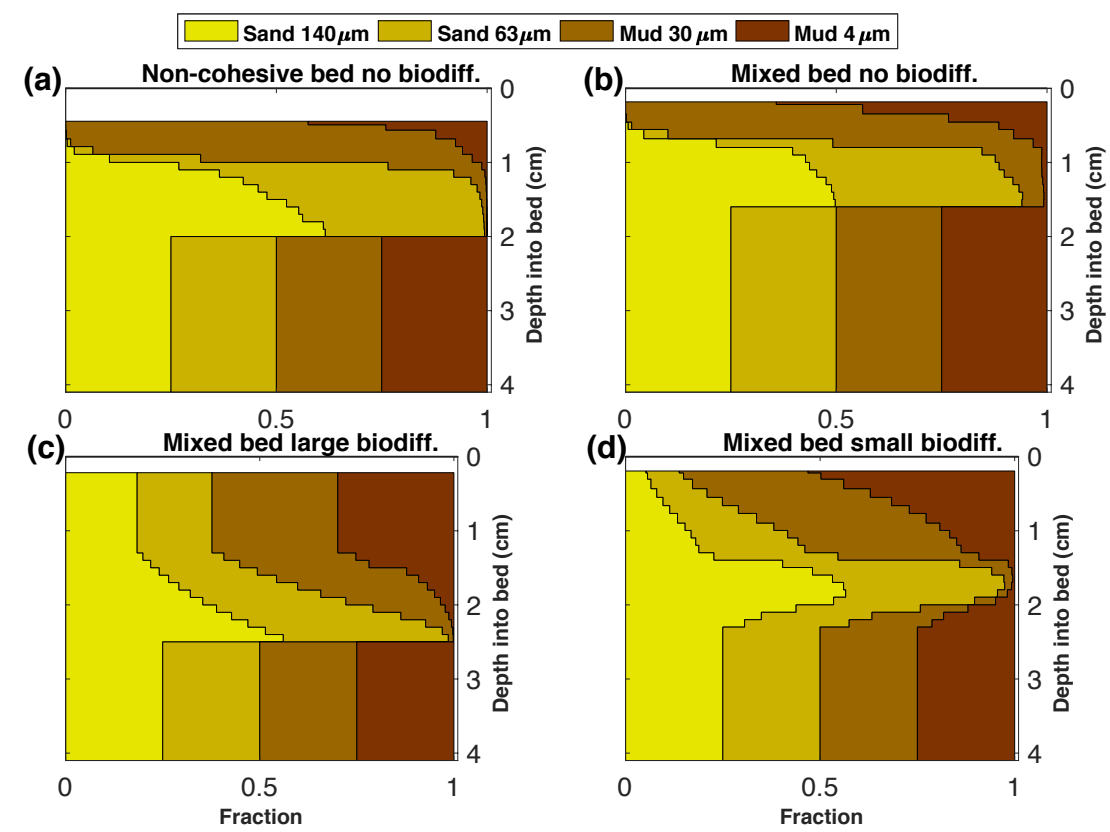

Figure 7. Comparison of final bed stratigraphy for resuspension and settling simulations showing the fraction of each sediment class distributed in each bed layer. (a) Non-cohesive bed with no biodiffusion (same as Fig. 5d, included for comparison); (b) mixed bed with no biodiffusion; (c) mixed bed with large biodiffusion $\left(D_{\mathrm{s}}=10^{-5} \mathrm{~m}^{2} \mathrm{~s}^{-1}\right)$; and (d) mixed bed with small biodiffusion $\left(D_{\mathrm{s}}=10^{-10} \mathrm{~m}^{2} \mathrm{~s}-1\right)$. The final sediment fraction distribution after two successive erosion-deposition events lasting 5 days (similar to Fig. 5b) is shown. The same four sediment classes were used in all experiments, but their cohesive behavior varied.

well mixed and the depth of the disturbed sediment at the end of the simulation was deeper $(2.5 \mathrm{~cm})$ in this case than in the other simulations. Sediment deeper than $2.5 \mathrm{~cm}$ below the surface was undisturbed: it was beyond the reach of erosion, active-layer formation, and biodiffusion. The biodiffusive mixing increased the recruitment of fine sediment into the surface active layer during erosion, resulting in increased concentrations in the water column (not shown) compared to the mixed-bed case without biodiffusion.

The case with a smaller biodiffusion coefficient (Fig. 7d) developed stratigraphy intermediate to those cases with large and zero biodiffusion. The depth of disturbed sediment was $2.3 \mathrm{~cm}$ and the transition between redeposited sand and mud was smooth with coarse sand being present at the surface of the bed. This gradual size gradation was intermediate to the sharp jump in the fractional distribution between mostly sandy layers and predominantly muddy layers produced in cases that neglected mixing (Fig. 7a, b) and the smooth gradient produced by the strong mixing case (Fig. 7c).

\subsection{Estuarine turbidity maxima}

High concentrations of suspended sediment often occur near the salt front in estuaries, forming estuary turbidity maxima (ETM). We present ETM test cases that simulated sediment transport in a two-dimensional (longitudinal and vertical) salt-wedge estuary with tidal and riverine forcing. The cases investigated the formation of cohesive deposits beneath the ETM with and without floc dynamics. The first case, without floc dynamics but with a mixed bed, is presented here. The second case, presented below, adds floc dynamics. The model was forced with a $12 \mathrm{~h}$ tidal oscillation modulated with a 14-day spring-neap cycle. The idealized estuary was $100 \mathrm{~km}$ long with a sloping bottom $4 \mathrm{~m}$ deep at the head of the estuary and $10 \mathrm{~m}$ deep at the mouth (Fig. 8a). In all cases, the simulations were run for 20 tidal cycles. Two non-cohesive sediment classes (180 and $250 \mu \mathrm{m}$ diameter) were represented with equal initial bed fractions $(50 \%$ of each). One cohesive fraction $\left(37 \mu \mathrm{m}, \rho_{\mathrm{f}}=1200 \mathrm{~kg} \mathrm{~m}^{-3}\right.$, $w_{\mathrm{s}}=0.13 \mathrm{~mm} \mathrm{~s}^{-1}$ ) was included, with an initial uniform suspended sediment concentration of $1 \mathrm{~kg} \mathrm{~m}^{-3}$. The bed was initialized without any cohesive sediment, so it initially behaved non-cohesively. Later in the simulation, bed behavior became mixed as suspended mud settled and was incorporated into the initially sandy bed. The chosen equilibrium bulk critical shear stress profile (Eq. 4) had a slope of $5 \ln \left(\mathrm{kg} \mathrm{m}^{-2}\right)$ and offset of $2 \ln \left(\mathrm{kg} \mathrm{m}^{-2}\right)$, with a minimum value of $0.05 \mathrm{~Pa}$ and a maximum of $2.2 \mathrm{~Pa}$. The timescale for consolidation was set to $T_{\mathrm{c}}=8 \mathrm{~h}$ (Sanford, 2008; Rinehimer et al., 2008), and the swelling timescale was set to $T_{\mathrm{s}}=33$ days.

During the simulations, the salinity and suspended sediment field evolved into dynamic equilibria that were repeated over consecutive tides. An estuarine turbidity maximum (ETM) developed between 10 and $60 \mathrm{~km}$ from the mouth of the estuary (Fig. 8a) in the salt wedge gener- 
ated by gravitational circulation and tidal straining (Burchard and Baumert, 1998; MacCready and Geyer, 2001). Elevated suspended sediment concentrations ranging from 0.7 to $2.05 \mathrm{~kg} \mathrm{~m}^{-3}$ occupied most of the bottom layer and extended to mid-depth. No floc dynamics were included, so all of the suspended material depicted in Fig. 8a was in the $37 \mu \mathrm{m}$ class.

The second case was identical, except that it included floc dynamics. Fifteen cohesive (floc) classes and the two noncohesive (sand) classes were included. Floc-class diameters were logarithmically spaced, ranging from 20 to $1500 \mu \mathrm{m}$, with floc densities ranging from 1350 to $1029.3 \mathrm{~kg} \mathrm{~m}^{-3}$ and settling velocities ranging from 0.078 to $5.31 \mathrm{~mm} \mathrm{~s}^{-1}$, commensurate with Eq. (1) with fractal dimension $n_{\mathrm{f}}=2$. The suspended sediment concentration field was initialized with a uniform concentration of $1 \mathrm{~kg} \mathrm{~m}^{-3}$, all in the $37 \mu \mathrm{m}$ class. The resulting ETM (Fig. 8b) extended farther up-estuary and contained much lower concentrations $\left(0.1\right.$ to $0.5 \mathrm{~kg} \mathrm{~m}^{-3}$ in most of the salt wedge, with a thin layer of higher concentrations $\left(2.1 \mathrm{~kg} \mathrm{~m}^{-3}\right)$ in the bottom layer (bottom $5 \%$ of the water column). The second layer (5-10\% of the water column) had concentrations about half of the bottom layer. The bed sediment response for the two cases also differed. In the no-floc case, the ETM deposit was slightly thinner, located closer to the mouth, and varied less from slack to flood (Fig. 8c). Floc dynamics created large tidal variations in the size of bed material (Fig. 8d), which ranged up to $600 \mu \mathrm{m}$ as flocs deposited during slack, and decreased to $37 \mu \mathrm{m}$ as flocs were resuspended during flood. The behavior in the unflocculated case was less intuitive. Over the course of the simulation, enough fine material accumulated beneath the ETM to cause the bed to behave cohesively, but the top active layer remained mostly non-cohesive. During flood tide, bottom stresses were sufficient to resuspend the non-cohesive $70 \mu \mathrm{m}$ material, leaving the cohesive $37 \mu \mathrm{m}$ material on the bed. Thus, in both cases, the bed became finer during period of higher stress, but for different reasons. The two cases highlight the model-dependent changes in location (driven primarily by settling velocities) and size distributions (driven by floc dynamics) of the ETM.

We next expanded the numerical experiment using six floc cases to elucidate the effects of floc dynamics in the idealized estuary (Table 1). The two-dimensional model domain was the same as the ETM case described above. Three types of floc behavior in the seabed were investigated: (1) no changes in size distribution occurred in the bed; (2) the floc evolution process in the bed was invoked, which nudged all cohesive sediment into the $20 \mu \mathrm{m}$ class over a long timescale $(50 \mathrm{~h})$; and (3) the floc evolution process was invoked with a short timescale $(5 \mathrm{~h})$. Additionally, three other combinations of aggregation $(\alpha)$ and disaggregation $(\beta)$ rates were used with the slow floc evolution in the bed rate to explore floc processes in the water column (Table 1). The following six metrics were compared at the location of the maximum depth-mean suspended sediment concentration (SSC): depth-mean SSC,
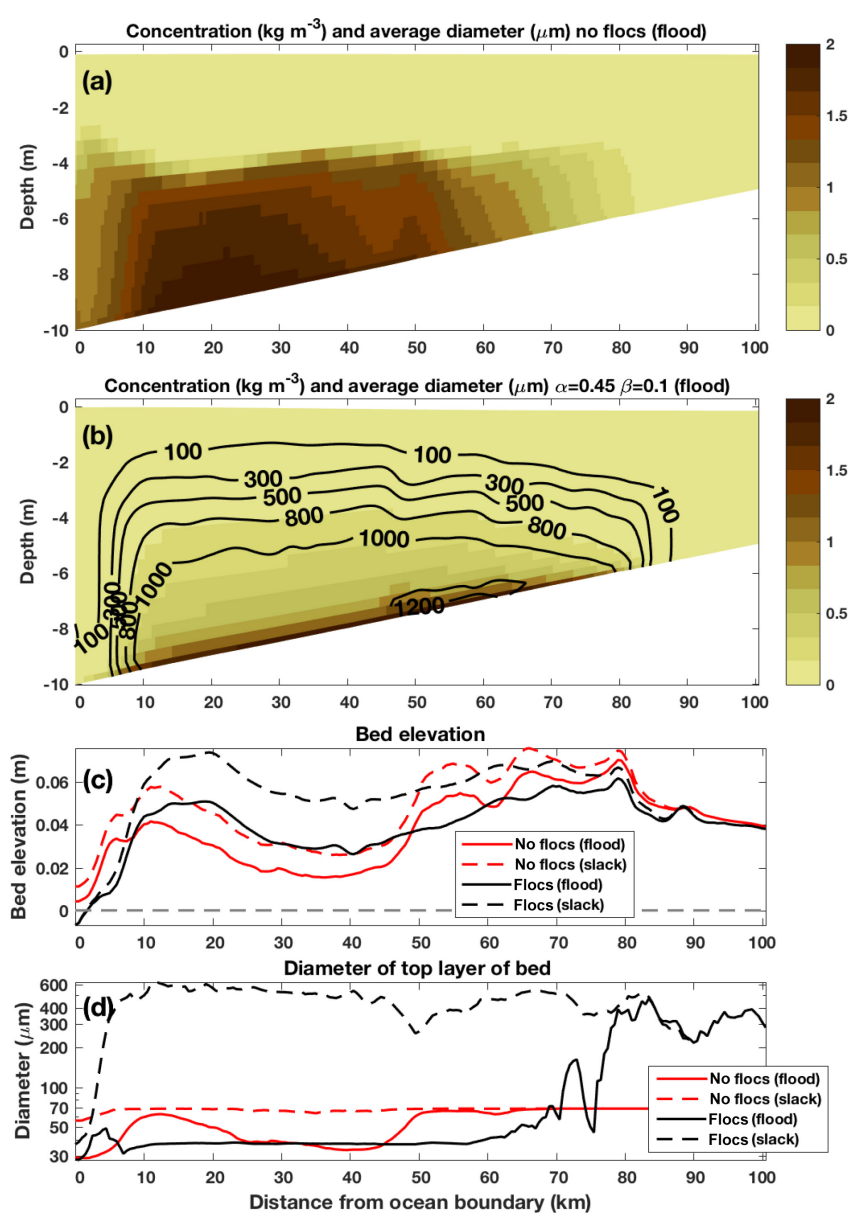

Figure 8. Comparison of estuarine turbidity maxima simulations with and without floc dynamics. (a) Two-dimensional (alongestuary and vertical) snapshot of suspended particle concentrations (shaded) without floc dynamics near the end of flood tide. All of the suspended material was in the $37 \mu \mathrm{m}$ class. (b) Snapshot of suspended particle concentrations at the same time in the simulation, but with simulated floc dynamics (shading), overlain by contours of mean particle diameters. (c) Along-estuary profiles of bed elevations for simulations without floc dynamics (red) and with floc dynamics (black) at the peak of flood tide (solid lines) and at postflood slack tide (dashed lines). (d) Along-estuary profiles of mean particle diameter in the top layer of the seabed using the same notation as $(\mathbf{c})$.

maximum SSC, median size $\left(D_{50}\right), 12 \mathrm{~h}$ mean of the $D_{50}$, depth-mean settling velocity $w_{\mathrm{s}}$, and depth-mean $w_{\mathrm{s}}$ averaged over a $12 \mathrm{~h}$ tidal period (Table 1). The median size and mean settling velocities were weighted by the mass in each class. Also listed in Table 1 are the locus of the maximum deposition, the thickness at that location, and the median size of deposited material at that location.

Mean SSC in the ETM did not vary significantly among the floc cases, but the maximum SSC (located lower in the water column) increased when the ratio of aggregation rate / disaggregation rate $\alpha / \beta$ was higher, which led to 
Table 1. Characteristics of the estuary turbidity maxima for seven cases under different flocculation conditions.

\begin{tabular}{|c|c|c|c|c|c|c|c|}
\hline Case & 0 & 1 & 2 & 3 & 4 & 5 & 6 \\
\hline & No flocs & $\begin{array}{r}\alpha=0.35 \\
\beta=0.15 \\
\text { no floc } \\
\text { evol. }\end{array}$ & $\begin{array}{r}\alpha=0.35 \\
\beta=0.15 \\
\text { floc evol., } \\
5 \mathrm{~h}\end{array}$ & $\begin{array}{r}\alpha=0.35 \\
\beta=0.15 \\
\text { floc evol., } \\
50 \mathrm{~h}\end{array}$ & $\begin{array}{r}\alpha=0.45 \\
\beta=0.10 \\
\text { floc evol., } \\
50 \mathrm{~h}\end{array}$ & $\begin{array}{r}\alpha=0.25 \\
\beta=0.20 \\
\text { floc evol., } \\
50 \mathrm{~h}\end{array}$ & $\begin{array}{r}\alpha=0.35 \\
\beta=0.34 \\
\text { floc evol., } \\
50 \mathrm{~h}\end{array}$ \\
\hline Mean SSC at maximum $\left(\mathrm{kg} \mathrm{m}^{-3}\right)$ & 1.23 & 0.46 & 0.45 & 0.45 & 0.45 & 0.46 & 0.46 \\
\hline Maximum SSC $\left(\mathrm{kg} \mathrm{m}^{-3}\right)$ & 3.1 & 3.6 & 3.7 & 3.7 & 4.1 & 3.2 & 2.9 \\
\hline $\begin{array}{l}D_{50} \text { at } \mathrm{SSC} \text { maximum }(\mu \mathrm{m}) \\
D_{50} \text { at } \mathrm{SSC} \text { maximum; }\end{array}$ & 37 & 539 & 529 & 529 & 622 & 426 & 384 \\
\hline $12 \mathrm{~h}$ mean $(\mu \mathrm{m})$ & 37 & 255 & 249 & 250 & 325 & 181 & 167 \\
\hline $\begin{array}{l}w_{\mathrm{s}} \text { at } \mathrm{SSC} \text { maximum }\left(\mathrm{mm} \mathrm{s}^{-1}\right) \\
w_{\mathrm{S}} \text { at } \mathrm{SSC} \text { maximum; }\end{array}$ & 0.13 & 1.91 & 1.87 & 1.87 & 2.2 & 1.51 & 1.36 \\
\hline $12 \mathrm{~h}$ mean $\left(\mathrm{mm} \mathrm{s}^{-1}\right)$ & 0.13 & 0.90 & 0.88 & 0.89 & 1.15 & 0.64 & 0.59 \\
\hline $\begin{array}{l}\text { Locus of maximum deposition } \\
\text { (km from ocean boundary) }\end{array}$ & $80 \pm 30$ & $19 \pm 11$ & $18 \pm 10$ & $18 \pm 114$ & $19 \pm 10$ & $79 \pm 69$ & $16 \pm 6$ \\
\hline Maximum deposit thickness (mm) & $4.2 \pm 5.8$ & $31.6 \pm 12.8$ & $25.8 \pm 10.1$ & $26.1 \pm 10.4$ & $27.1 \pm 10.9$ & $5 \pm 10.1$ & $25 \pm 10.2$ \\
\hline Maximum deposit $D_{50}(\mu \mathrm{m})$ & $18.5 \pm 0$ & $218 \pm 87.1$ & $40.9 \pm 71.3$ & $75.5 \pm 76.1$ & $92.9 \pm 94.2$ & $69.5 \pm 89.9$ & $25.4 \pm 40.4$ \\
\hline
\end{tabular}

larger, faster-settling flocs. Among the four cases (3-6) with slow floc evolution rates in the bed, settling velocities, maximum SSC, and floc size covaried. The locus of the maximum deposition of ETM material was insensitive to the algorithms for floc evolution in the bed (cases 1-3) and most sensitive to the overall floc rates. The range of ETM locations is listed in Table 1 to highlight the cases in which ETM location varied. The case with lowest floc rates (case 5) produced the farthest upriver deposit, with the most variation in the location of the maximum. The case with the highest settling velocities (case 6) produced deposits closest to the estuary mouth. Overall, the simulated ETM was more sensitive to changes in floc parameters than to the prescribed behavior of the floc evolution in the seabed, and the greatest effect of varying floc dynamics was the vertical location of the ETM, which was controlled by floc size and settling velocity.

\section{Realistic application: York River estuary}

This section demonstrates the cohesive sediment bed model in a realistic domain representing the York River, a subestuary of Chesapeake Bay (Fig. 9). Recent modeling efforts have focused on this location as part of a program aimed at exploring links between cohesive sediment behavior, benthic ecology, and light attenuation. As part of this program, colleagues have obtained complementary field observations there, which have been especially focused on the two locations off Gloucester Point and Clay Bank, VA (e.g., Dickhudt et al., 2009, 2011; Cartwright et al., 2013). The implementation presented here is similar to the three-dimensional model developed by Fall et al. (2014) that accounted for circulation, sediment transport, and a cohesive bed. While this model neglects flocculation, information obtained by field observations such as the study by Cartwright et al. (2013) have been

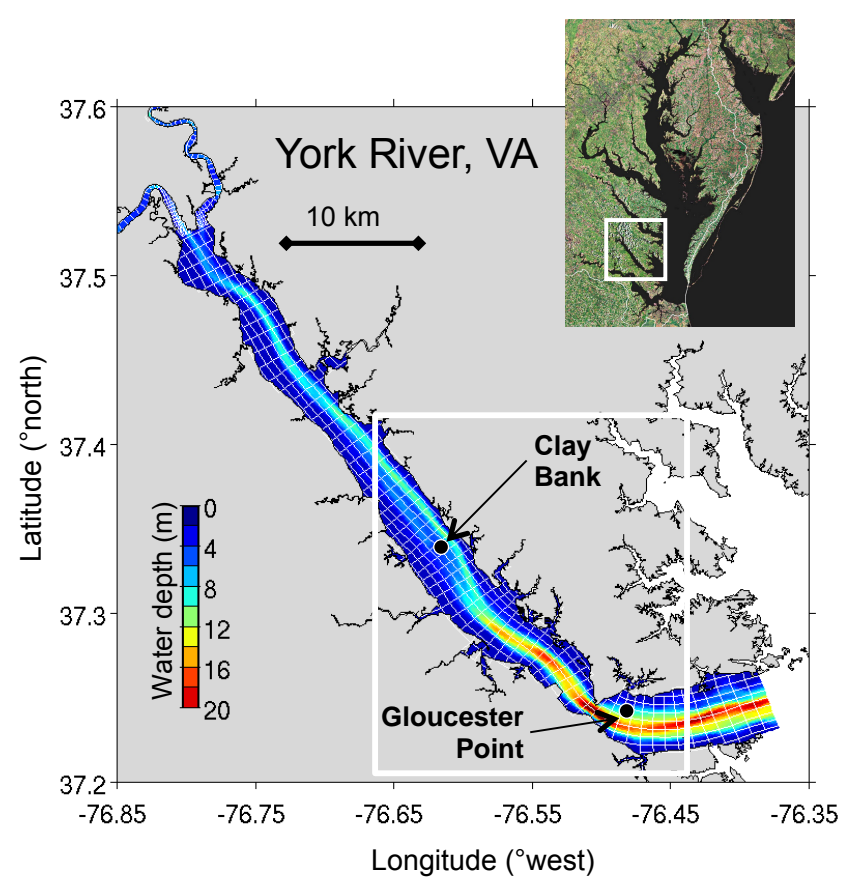

Figure 9. York River bathymetry (color scale) and model grid (white lines show every fifth grid line in the along- and acrosschannel directions). The inset satellite image shows the location of the York River in Chesapeake Bay. The region outlined in white is expanded in Fig. 10.

consulted for guidance in setting settling velocities of the cohesive particles. The model is run assuming muddy behavior of the bed and neglecting mixed-bed processes because the majority of sediment transport within the York River channels consists of fine-grained material. We found that it was important to modify the sediment bed layering management 

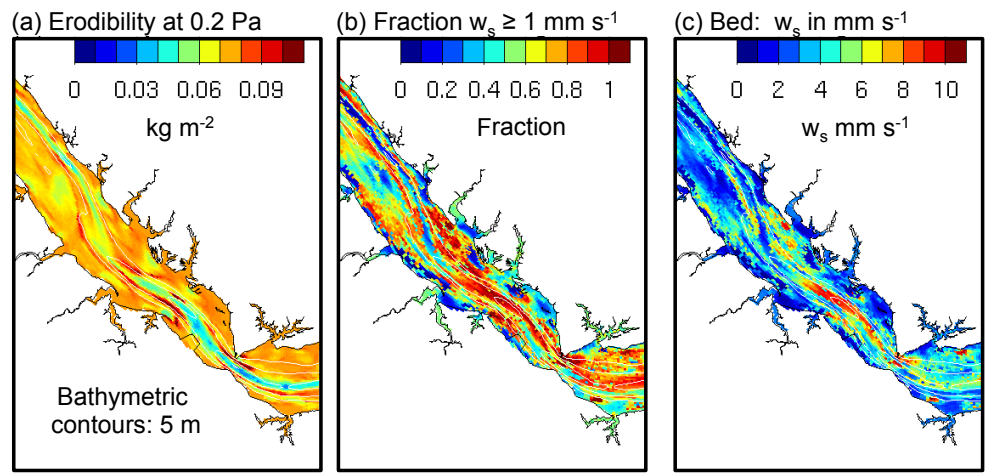

Figure 10. Model estimates of seabed properties after 2 months of tidal forcing and constant average freshwater discharge. (a) Erodibility of the seabed, calculated as the thickness of the layer having a critical shear stress exceeded by $0.2 \mathrm{~Pa}$. (b) Fraction of the surficial sediment in the faster-settling size class. (c) Average settling velocity of surficial sediment.

scheme, as discussed in Sect. 5 below, to resolve the high gradients in bed erodibility evident in the sediment bed model (i.e., Fall et al., 2014) and data (i.e., Dickhudt et al., 2009, 2011).

In this implementation, sediment deposited to the bed provided an easily erodible layer with an assumed low critical stress, $\tau_{\mathrm{c}}=0.05 \mathrm{~Pa}$. The modeled sediment bed erodibility and suspended sediment concentrations were both found to be sensitive to the parameterization of the equilibrium critical stress profile and to the consolidation and swelling timescales used (Fall et al., 2014). Here we present a case similar to that shown by Fall et al. (2014), but that differs mainly in terms of the sediment bed initialization. The equilibrium critical stress profile was chosen as $\tau_{\mathrm{cbeq}}=z_{\mathrm{p}}^{0.62}$, which was a power-law fit to the erodibility experiments performed by Dickhudt (2008) on field-collected cores in September 2007 (Rinehimer et al., 2008). Swelling and consolidation timescales of 1 and 50 days, respectively, were used. Both the porosity $(\theta=0.9)$ and the erosion rate parameter $E_{0}=0.03 \mathrm{~kg} \mathrm{~m}^{-2} \mathrm{~s}^{-1} \mathrm{~Pa}^{-1}$ ) were held constant. A zerogradient condition was applied for the suspended sediment concentration at the open boundary where the York River meets Chesapeake Bay. Six sediment classes that had settling velocities ranging from 0.032 to $10 \mathrm{~mm} \mathrm{~s}^{-1}$ were used. To initialize the seabed, they were distributed in equal fractions throughout the model domain in a 20-layer sediment bed that had a total thickness of $1 \mathrm{~m}$, with all but the bottom layer being thin $(0.1 \mathrm{~mm})$. In this way, the model was initialized with a sediment bed that had high vertical resolution $(0.1 \mathrm{~mm})$ in the upper $\sim 2 \mathrm{~cm}$ underlain by a thick layer $(\sim 1 \mathrm{~m})$ sediment. This created high vertical resolution in the bulk critical shear stress profile near the sediment-water interface, while still providing a fairly large pool of sediment so that erosional locations retained some sediment in the seabed throughout the model run. Bed critical stress was initialized everywhere to be constant $(0.05 \mathrm{~Pa})$ with depth and quickly evolved to the equilibrium critical shear stress profile at the compaction timescale of a few days. The model was run to represent 2 months using the 60 -year median freshwater flow of $67 \mathrm{~m}^{3} \mathrm{~s}^{-1}$ and a spring-neap tidal cycle with a $0.2 \mathrm{~m}$ neap amplitude and $0.4 \mathrm{~m}$ spring amplitude.

The initially uniform bed evolved during the 60-day model run, developing areas of high sediment erodibility along the shoals of the estuary and channel flanks (Fig. 10a). In general, sediment was removed from the main channel, which developed reduced erodibility (Fig. 10a). At the Gloucester Point site, the initial bed evolved to become less erodible, with a critical shear stress at the seabed that exceeded the equilibrium values specified for the model (Fig. 10a). Conversely, at the Clay Bank field site, conditions were variable in space. Sediment deposited on the shoal area, which evolved to enhanced erodibility (Fig. 10a). Within the channel, however, the equilibrium critical stress for erosion was often exceeded, resulting in a strongly eroded sediment bed having larger values of critical shear at the sediment surface (Fig. 10a). Resuspension and transport also changed the spatial distribution of sediment classes, with the erosional areas retaining only the coarser, faster-settling classes, while depositional areas retained finer-grained, slower-settling particles (Fig. 10b, c). These patterns, with coarse lag layers and reduced erodibility in the channels relative to the shoals, are consistent with the known grain size distributions and properties of the York River estuary.

\section{Discussion}

The model algorithms presented here were motivated by the need to improve the representations of sediment dynamics in numerical models of fine-grained and mixed-sediment environments. The improvements were implemented in the COAWST version of ROMS, which provides a framework for realistic two-way nested models with forcing from meteorology (WRF; Michalakes et al., 2001) and waves (either SWAN: Booij et al., 1999; or WaveWatch III; Tol- 
man and the WAVEWATCH III Development Group, 2014). Waves, in particular, play an important role in cohesive sediment dynamics through wave-enhanced bottom shear stresses, wave-induced near-bottom turbulence, and waveinduced nearshore circulation, but wave-induced fluid-mudlayer processes are not represented. ROMS includes options for several turbulence sub-models (e.g., $k-\varepsilon, k-\omega$, Mellor-Yamada) and wave current bottom-boundary-layer sub-models that allow us to calculate fields of shear velocity $G$. The implementation of FLOCMOD in this framework provides a platform for numerical experiments and the realworld applications of a full-featured floc model.

The primary role of the floc model is to simulate the dynamical response of particle settling velocities to spatial and temporal variations in shear and suspended sediment concentrations. This can also be achieved with simpler and computationally more efficient parameterization in many applications. What are the advantages of the complex and much slower model implemented here? There are several. The floc model provides fields of particles with a dynamically varying density and number of primary particles, which allow for the calculation of the acoustic and optical responses of the particle fields. In turn, this allows for direct comparison with field measurements of light attenuation, optical backscatter, and acoustic backscatter, the de facto proxies for suspended sediment concentration. This also allows for the calculation of derived properties in the water column, including light penetration and diver visibility. Finally, the modeled particle properties can be used in geochemical calculations that require estimates of particle radius, porosity, and reactive surface area. Depending on the application, this additional information may justify the computational expense of the floc model.

The cohesive bed model provides a heuristic but demonstrably useful tool for representing muddy and mixed beds. The cohesive bed framework captures the most important aspects of a muddy environment: limitations on erosion caused by increased bed strength with depth in the sediment and changes toward user-defined equilibrium conditions as deposited (or eroded) beds age. The physical processes of selfcompaction and the associated changes in porosity and bed strength are not modeled, but the framework of particle-class and bed-layer variables are designed to accommodate a compaction algorithm. The equilibrium profile method implemented here adds little computational expense, but allows the model to represent depth-limited erosion, a key property of many cohesive beds.

Modeling stratigraphy effectively is challenging. Although conserving sediment mass among a fixed number of layers is straightforward, it has proven difficult to devise a robust and efficient method that records relevant stratigraphic events in a modeled sediment bed over the wide range of conditions that occur in coastal domains. For both sediment transport and sediment bed geochemistry (i.e., Moriarty et al., 2017; Birchler et al., 2018), it can be important for the sediment bed model to achieve its highest vertical resolution near the sediment-water interface, but the original ROMS sediment bed model did not meet that goal when the sediment bed was subject to frequent or repeated cycles of erosion. The modifications we have made to the bed-layer management have improved the fidelity with which we can record stratigraphic events in the model layers, particularly at the sediment-water interface. The inclusion of biodiffusive mixing is important for environments where biological activity is rapid compared with sedimentation or physical reworking. Additionally, for problems of sediment geochemistry, it is important to account for the mixing of both particulate matter and porewater. Expansion of the ROMS sediment bed model to include diffusive mixing facilitates its use for interdisciplinary problems (i.e., Moriarty et al., 2017; Birchler et al., 2018). The choice of appropriate mixing parameters remains a challenge, especially when considering the spatial and seasonal heterogeneity of biological activity.

Overall, the cohesive and mixed-bed algorithms we have introduced in ROMS provide tools that should be useful for both numerical experimentations and realistic applications for fine-grained and mixed-bed environments. The model applies to dilute suspensions at a high Reynolds number (fully turbulent flow) because the turbulence sub-models do not account for particle influences on turbulence dissipation or momentum transfer (e.g., Hsu et al., 2003; Le Hir et al., 2000; Mehta, 1991, 2014), so fluid muds and nonNewtonian flows are not represented. We have not quantified the sediment concentrations or range of hydrodynamic parameters for which the model approximations are valid, but a common boundary for fluid mud (in which viscoplastic properties become important) is $10 \mathrm{~kg} \mathrm{~m}^{-3}$ (Einstein and Krone, 1962; Kirby, 1988). Other processes associated with cohesive or mixed sediment that have not been included are flow-induced infiltration of fine material into a porous bed (Huettel et al., 1999), changes to the erodibility of mud that has been exposed at low tide (e.g., Paterson et al., 1990; Pilditch et al., 2008), and changes to erodibility caused by flora or fauna (e.g., de Boer, 1981; de Deckere et al., 2001; Malarkey et al., 2015; Parsons et al., 2016). The floc model does not explicitly account for the effects of organic matter content, $\mathrm{pH}$, or salinity on flocculation rate (e.g., Mietta et al., 2009); these influences are subsumed into useradjustable parameters. It is important to note that the mass settling fluxes of mixed (sand + mud) suspensions may be overestimated if their interactions are not considered, as is the case in the approach taken here (Manning et al., 2010, 2011; Spearman et al., 2011). Nonetheless, our implementation of flocculation, bed consolidation, and bed-mixing modules enhances the utility of the ROMS sediment model for interdisciplinary studies including ecosystem feedbacks (light attenuation, biogeochemistry) and contaminant transport. 


\section{Conclusion}

This paper describes three ways in which the sediment model of Warner et al. (2008) has been enhanced, allowing simulations to be made for non-cohesive, cohesive, and mixed sediment and allowing it to be applied in a wider range of studies. A flocculation model has been added, following Verney et al. (2011). The cohesive bed model developed by Sanford (2008) has been added, allowing the erodibility of the sediment bed to evolve in response to the erosional and depositional history. Mixing between bed layers has been implemented as biodiffusion using a user-specified diffusion coefficient profile. In addition, the sediment bed layering routine has been modified so that bed layers maintain a high resolution near the sediment-water interface, as demonstrated by both our idealized and realistic case studies presented here. The paper presents results of model runs that test and demonstrate these new features and shows their application to realworld systems. The authors encourage the coastal modeling community to use, evaluate, and improve upon the new routines.

Code and data availability. The algorithms described here have been implemented in ROMS (version 3.6) distributed with the Coupled Ocean-Atmosphere-Wave-Sediment Transport Modeling System (COAWST, Subversion repository revision number 1234). COAWST is an open-source community modeling system with a subversion source-control system maintained by John C. Warner (jcwarner@usgs.gov) and distributed under the MIT/X License (Warner et al., 2010). The COAWST distribution files contain source code derived from ROMS, WRF, SWAN, MCT, and SCRIP, along with MATLAB code, examples, and a user manual.

\section{The Supplement related to this article is available online at https://doi.org/10.5194/gmd-11-1849-2018- supplement.}

Author contributions. CRS and AA shared the development of the model code and test cases and most of the paper preparation. JPR was an early user of the cohesive bed model and, along with $\mathrm{CKH}$, developed the York River application. RV graciously supplied his FORTRAN version of FLOCMOD and helped with adaptation for ROMS. BF contributed to the early development and application of the model. All authors contributed to the final version.

Competing interests. The authors declare that they have no conflict of interest.

Disclaimer. Use of firm and product names is for descriptive purposes only and does not imply endorsement by the US government.
Acknowledgements. The authors thank Jeremy Spearman, Alexis Beudin, Julia Moriarity, and five anonymous reviewers (two from Ocean Dynamics and three from Geoscientific Model Development) for helpful comments on earlier drafts of this paper. This work was supported by the US Geological Survey, Coastal and Marine Geology Program and the National Ocean Partnership Program. Courtney K. Harris was supported by the NSF (OCE-1459708, OCE-1061781, and OCE-0536572). This paper is contribution number 3741 of the Virginia Institute of Marine Science, College of William \& Mary. Bénédicte Ferré is affiliated with the Centre of Excellence: Arctic Gas hydrate, Environment and Climate (CAGE) funded by the Norwegian Research Council (grant no. 223259). The model code is implemented in ROMS version 3.6, as distributed with the COAWST modeling system (Subversion repository revision 1234; Warner et al., 2010), and is freely available by request to John C. Warner (jcwarner@usgs.gov) at the US Geological Survey.

Edited by: Guy Munhoven

Reviewed by: three anonymous referees

\section{References}

Amoudry, L. O. and Souza, A. J.: Deterministic coastal morphological and sediment transport modeling: a review and discussion, Rev. Geophys., 49, RG2002, https://doi.org/10.1029/2010RG000341, 2011.

Ariathurai, R. and Arulanandan, K.: Erosion Rates of Cohesive Soils, Journal of Hydraulic Division, ASCE, 104, 279-283, 1978.

Booij, N., Ris, R. C., and Holthuijsen, L. H.: A thirdgeneration wave model for coastal regions: 1. Model description and validation, J. Geophys. Res., 104, 7649-7666, https://doi.org/10.1029/98JC02622, 1999.

Boudreau, B. P.: Is burial velocity a master parameter for bioturbation?, Geochim. Cosmochim. Ac., 58, 1243-1250, 1994.

Boudreau, B. P.: Diagenetic Models and Their Implementation, Springer-Verlag, Berlin, 414 pp., 1997.

Beudin, A., Kalra, T. S., Ganju, N. K., and Warner, J. C.: Development of a Coupled Wave-Flow-Vegetation Interaction Model, Comput. Geosci., 100, 76-86, https://doi.org/10.1016/j.cageo.2016.12.010, 2017.

Birchler, J. J., Harris, C. K., Kniskern, T. A., and Sherwood, C.R .: Numerical model of geochronological tracers for deposition and reworking applied to the Mississippi subaqueous delta, J. Coast Res., SI 85: 1-5, https://doi.org/10.2112/SI85-001.1, 2018.

Burchard, H. and Baumert, H.: The formation of estuary turbidity maxima due to density effects in the salt wedge. A hydrodynamic process study, J. Phys. Oceanogr., 20, 309-321, 1998.

Butman B., Aretxabaleta, A. L., Dickhudt, P. J., Dalyander, P. S., Sherwood, C. R., Anderson, D. M., Keafer, B. A., and Signell, R. P.: Investigating the importance of sediment resuspension in Alexandrium fundyense cyst population dynamics in the Gulf of Maine, Deep-Sea Res. Pt. II, 103, 74-95, https://doi.org/10.1016/j.dsr2.2013.10.011, 2014.

Caldwell, R. L. and Edmonds, D. A.: The effects of sediment properties on deltaic processes and morphologies: A numer- 
ical modeling study, J. Geophys. Res.-Earth, 119, 961-982, https://doi.org/10.1002/2013JF002965, 2014.

Cartwright, G. M., Friedrichs, C. T., and Smith, J. S.: A test of the ADV-based Reynolds-flux method for in situ estimation of sediment settling velocity in a muddy estuary, Geo-Mar. Lett., 33, 477-484, https://doi.org/10.1007/s00367-013-0340-4, 2013.

de Boer, P. L.: Mechanical effects of micro-organisms on intertidal bedform migration, Sedimentology, 28, 129-132, https://doi.org/10.1111/j.1365-3091.1981.tb01670.x, 1981.

de Deckere, E. M. G. T., Tolhurst, T. J., and de Brouwer, J. F. C.: Destabilization of Cohesive Intertidal Sediments by Infauna, Estuar. Coast. Shelf S., 53, 665-669, https://doi.org/10.1006/ecss.2001.0811, 2001.

del Barrio, P., Ganju, N. K., Aretxabaleta, A. L., Hayn, M., García, A., and Howarth, R. W.: Modeling Future Scenarios of Light Attenuation and Potential Seagrass Success in a Eutrophic Estuary, Estuar. Coast. Shelf S., 149, 13-23, https://doi.org/10.1016/j.ecss.2014.07.005, 2014.

Dickhudt, P. J.: Controls on erodibility in a partially mixed estuary: York River, Virginia, MS thesis, College of William and Mary, Gloucester Point, VA, 2008.

Dickhudt, P. J., Friedrichs, C. T., Schaffner, L. C., and Sanford, L. P.: Spatial and temporal variation in cohesive sediment erodibility in the York River estuary, eastern USA: A biologically influenced equilibrium modified by seasonal deposition, Mar. Geol., 267, 128-140, https://doi.org/10.1016/j.margeo.2009.09.009, 2009.

Dickhudt, P. J., Friedrichs, C. T., and Sanford, L. P.: Mud matrix solids fraction and bed erodibility in the York River estuary, USA, and other muddy environments, Cont. Shelf Res., 31, S3S13, https://doi.org/10.1016/j.csr.2010.02.008, 2011.

DiToro, D. M.: Sediment Flux Modeling, Wiley-Interscience, New York, 624 pp., 2001.

Ditschke, D. and Markofsky, M.: A time-dependent flocculation model, in: Sediment and Ecohydraulics - INTERCOH 2005, Proceedings in Marine Science, edited by: Kusuda, T., Yamanishi, H., Spearman, J., and Gailani, J. Z., Elsevier, Amsterdam, 9, 241-253, https://doi.org/10.1016/S15682692(08)80019-8, 2008.

Droppo, I. G., Leppard, G. G., Liss, S. N., and Milligan, T. G.: Opportunities, needs, and strategic direction for research on flocculation in natural and engineered systems, in: Flocculation in Natural and Engineered Environmental Systems, edited by: Droppo, I. G., Leppard, G. G., Liss, S. N., and Milligan, T. G., CRC Press, London, 407-421, 2005.

Dyer, K. R.: Coastal and Estuarine Sediment Dynamics, John Wiley and Sons, Chichester, 1986.

Edmonds, D. A. and Slingerland, R. L.: Significant effect of sediment cohesion on delta morphology, Nat. Geosci., 3, 105-109, https://doi.org/10.1038/ngeo730, 2010.

Einstein H. A. and Krone R. B.: Experiments to determine modes of cohesive sediment transport in salt water, J. Geophys. Res., 67, 1451-1461, https://doi.org/10.1029/JZ067i004p01451, 1962.

Eisma, D.: Flocculation and de-flocculation of suspended matter in estuaries, Neth. J. Sea Res., 20, 183-199, 1986.

Fall, K. A., Harris, C. K., Friedrichs, C. T., Rinehimer, J. P., and Sherwood, C. R.: Model behavior and sensitivity in an application of the cohesive bed component of the Community Sediment Transport Modeling System for the York
River Estuary, VA, USA, J. Mar. Sci. Eng., 2, 413-436, https://doi.org/10.3390/jmse2020413, 2014.

Fasham, M. J. R., Ducklow, H. W., and McKelvie S. M.: A nitrogenbased model of plankton dynamics in the oceanic mixed layer, J. Mar. Res., 48, 591-639, 1990.

Fennel, K., Wilkin, J., Levin, J., Moisan, J., and O'Reilly, J.: Nitrogen cycling in the Middle Atlantic Bight: Results from a three-dimensional model and implications for the North Atlantic nitrogen budget, Global Biogeochem. Cy., 20, GB3007, https://doi.org/10.1029/2005GB002456, 2006.

Harris, C. K. and Wiberg, P. L.: Approaches to quantifying longterm continental shelf sediment transport with an example from the northern California STRESS mid-shelf site, Cont. Shelf Res., 17, 1389-1418, 1997.

Harris, C. K. and Wiberg, P. L.: A two-dimensional, time-dependent model of suspended sediment transport and bed reworking for continental shelves, Comput. Geosci., 27, 675-690, 2001.

Hill, P. S. and Nowell, A. R. M.: Comparison of two models of aggregation in continental-shelf bottom boundary layers, J. Geophys. Res., 100, 22749-22763, 1995.

Hirano, M.: River bed degradation with armouring, in: Proceedings, Japan Society of Civil Engineers, Japan, 195, 55-65, https://doi.org/10.2208/jscej1969.1971.195_55, 1971.

Hsu T.-J., Jenkins, J. T., and Liu, P. L.-F.: On two-phase sediment transport: Dilute flow, J. Geophys. Res., 108, 3057 , https://doi.org/10.1029/2001JC001276, 2003.

Huettel, M., Ziebis, W., and Forster, S.: Flow-induced uptake of particulate matter in permeable sediments, Limnol. Oceanogr., 41, 309-322, https://doi.org/10.4319/lo.1996.41.2.0309, 1999.

HydroQual, Inc.: A Primer for ECOMSED Version 1.4 Users Manual, HydroQual, Inc., Mahwah, NJ, 2004.

Jacobs, W., Le Hir, P., Van Kesteren, W., and Cann, P.: Erosion threshold of sand - mud mixtures, Cont. Shelf Res., 31, S14 S25, https://doi.org/10.1016/j.csr.2010.05.012, 2011.

Keyvani, A. and Strom, K.: Influence of Cycles of High and Low Turbulent Shear on the Growth Rate and Equilibrium Size of Mud Flocs, Mar. Geol., 354, 1-14, https://doi.org/10.1016/j.margeo.2014.04.010, 2014.

Khelifa, A. and Hill, P. S.: Models for effective density and settling velocity of flocs, J. Hydraul. Res., 44, 390-401, 2006.

Kirby, R.: High Concentration Suspension (Fluid Mud) Layers in Estuaries, in: Physical Processes in Estuaries, edited by: Dronkers, J. and van Leussen, W., Springer, Berlin, Heidelberg, 463-487, https://doi.org/10.1007/978-3-642-73691-9_23, 1988.

Knoch, D. and Malcherek, A.: A numerical model for simulation of fluid mud with different rheological behaviors, Ocean Dynam., 61, 245-256, https://doi.org/10.1007/s10236-010-0327-x, 2011.

Kranenburg, C.: The fractal structure of cohesive sediment aggregates, Estuar. Coast. Shelf Sci., 39, 451-460, 1994.

Krone, R. B.: Flume studies of the transport of sediment in estuarial shoaling processes, Final Report, Hydraulic Engineering Laboratory and Sanitary Engineering Research Laboratory, Univ. of California, Berkeley, 1962

Le Hir, P., Bassoullet, P., and Jestin, H.: Application of the continuous modeling concept to simulate high-concentration suspended sediment in a macrotidal estuary, in: Proceedings in Marine Science, Coastal and Estuarine Fine Sediment Processes, edited by: McAnally, W. H. and Mehta, A. J., Elsevier, 229-247, https://doi.org/10.1016/S1568-2692(00)80124-2, 2000. 
Le Hir, P., Cayocca, F., and Waeles, B.: Dynamics of sand and mud mixtures: A multiprocess-based modelling strategy, Cont. Shelf Res., 3, S135-S149, 2011.

Lecroart, P., Maire, O., Schmidt, S., Grémare, A., Anschutz, P., and Meysman F. J. R.: Bioturbation, short-lived radioisotopes, and the tracer-dependence of biodiffusion coefficients, Geochim. Cosmochim. Ac., 74, 21, 6049-6063, https://doi.org/10.1016/j.gca.2010.06.010, 2010

Letter, J. V.: Significance of probabilistic parameterization in cohesive sediment bed exchange, $\mathrm{PhD}$ thesis, Univ. of Florida, Gainesville, 2009.

Letter, J. V. and Mehta, A. J.: A heuristic examination of cohesive sediment bed exchange in turbulent flows, Coast. Eng., 58, 779789, 2011

Li, Q. W., Benson M. Harlan, M., Robichaux, P., Sha, X., $\mathrm{Xu}, \mathrm{K}$., and Straub, K. M.: Influence of sediment cohesion on deltaic morphodynamics and stratigraphy over basinfilling time scales, J. Geophys. Res.-Earth, 122, 1808-1826, https://doi.org/10.1002/2017JF004216, 2017.

Lick, W., Huang, H., and Jepsen, R.: Flocculation of fine-grained sediment due to differential settling, J. Geophys. Res., 98, 10279-10288, 1993.

Lumborg, U.: Modelling the deposition, erosion, and flux of cohesive sediment through Oresund, J. Mar. Syst., 56, 179-193, 2005.

Lumborg, U. and Pejrup, M.: Modelling of cohesive sediment transport in a tidal lagoon - an annual budget, Mar. Geol., 218, 1-16, 2005.

Lumborg, U. and Windelin, A.: Hydrography and cohesive sediment modelling: application to the Romo Dyb tidal area, J. Mar. Syst., 38, 287-303, 2003.

Maa, J. P.-Y., Sanford, L. P., and Schoellhamer, D. H. (Eds): Estuarine and Coastal Fine Sediment Dynamics: INTERCOH 2003, vol. 8, Proceedings in Marine Science, Elsevier, Amsterdam, 2007.

MacCready, P. and Geyer, W. R.: Estuarine salt flux through an isohaline surface, J. Geophys. Res., 106, 11629-11637, 2001.

MacDonald, I., Vincent, C. E., Thorne, P. D., and Moate, B. D.: Acoustic scattering from a suspension of flocculated sediments, J. Geophys. Res., 118, 2581-2594, https://doi.org/10.1002/jgrc.20197, 2013.

Maerz, J., Verney, R., Wirtz, K., and Feudel, U.: Modeling flocculation processes: Intercomparison of a size class-based model and a distribution-based model, Cont. Shelf Res., 31, S84-S93, https://doi.org/10.1016/j.csr.2010.05.011, 2011.

Malarkey, J., Baas, J. H., Hope, J. A., Aspden, R. J., Parsons, D. R., Peakall, J., Paterson, D. M., Schindler, R. J., Ye, L., Lichtman, I. D., Bass, S. J., Davies, A. G., Manning, A. J., and Thorne, P. D.: The pervasive role of biological cohesion in bedform development, Nat. Commun., 6, 6257, https://doi.org/10.1038/ncomms7257, 2015.

Manning, A. J. and Dyer, K. R.: Mass settling flux of fine sediments in Northern European estuaries: measurements and predictions, Mar. Geol., 245, 107-122, 2007.

Manning, A. J., Baugh, J. V., Spearman, J. R., and Whitehouse, R. J. S.: Flocculation settling characteristics of mud: sand mixtures, Ocean Dynam., 60, 237-253, https://doi.org/10.1007/s10236009-0251-0, 2010.

Manning, A. J., Baugh, J. V., Spearman, J. R., Pidduck, E. L., and Whitehouse, R. J. S.: The settling dynamics of flocculating mud-sand mixtures: Part 1 - Empirical algorithm development, Ocean Dynam., 61, 311-350, https://doi.org/10.1007/s10236011-0394-7, 2011.

McCave, I. N.: Size spectra and aggregation of suspended particles in the deep ocean, Deep-Sea Res., 31, 329-352, 1984.

McCave, I. N. and Swift, S. A.: A physical model for the deposition of fine-grained sediments in the deep sea, GSA Bulletin, 87, 541546, 1976.

Mehta, A. J.: Characterization of cohesive sediment properties and transport processes in estuaries, in: Lecture Notes on Coastal and Estuarine Studies, edited by: Mehta, A. J., Springer, Berlin, 14, 290-325, 1986.

Mehta, A. J.: Understanding fluid mud in a dynamic environment, Geo-Mar. Lett., 11, 113-118, https://doi.org/10.1007/BF02430995, 1991.

Mehta, A. J.: An Introduction to the Hydraulics of Fine Sediment Transport, World Scientific, 1039 pp, 2014.

Mehta, A. J., Manning, A. J., and Khare, Y. P.: A note on the Krone deposition equation and significance of floc aggregation, Mar. Geol., 354, 34-39, https://doi.org/10.1016/j.margeo.2014.04.002, 2014.

Mengual, B., Hir, P.L., Cayocca, F., and Garlan, T.: Modelling Fine Sediment Dynamics: Towards a Common Erosion Law for Fine Sand, Mud and Mixtures, Water, 9, 564, https://doi.org/10.3390/w9080564, 2017.

Merkel, U. H. and Kopmann, R.: A continuous vertical grain sorting model for Telemac \& Sisyphe, in: River Flow 2012, edited by: Munoz, R. M., Taylor \& Francis, London, 2012.

Michalakes, J., Chen, S., Dudhia, J., Hart, L., Klemp, J., Middlecoff, J., and Skamarock, W.: Development of a nextgeneration regional weather research and forecast model, in: Developments in Teracomputing, World Scientific, 269-276, https://doi.org/10.1142/9789812799685_0024, 2001.

Mietta, F., Chassagne, C., Manning, A. J., and Winterwerp, J. C.: Influence of shear rate, organic matter content, $\mathrm{pH}$ and salinity on mud flocculation, Ocean Dynam., 59, 751-763, https://doi.org/10.1007/s10236-009-0231-4, 2009.

Mitchener, H. and Torfs, H.: Erosion of mud/sand mixtures, Coast. Eng., 29, 1-25, 1996.

Moriarty, J. M., Harris, C. K., Fennel, K., Friedrichs, M. A. M., $\mathrm{Xu}, \mathrm{K}$., and Rabouille, C.: The roles of resuspension, diffusion and biogeochemical processes on oxygen dynamics offshore of the Rhône River, France: a numerical modeling study, Biogeosciences, 14, 1919-1946, https://doi.org/10.5194/bg-141919-2017, 2017.

Nguyen, H.-H. and Chua, L. H. C.: Simplified physically based model for estimating effective floc density, J. Hydraul. Eng., 137, 843-846, 2011.

Panagiotopoulos, I., Voulgaris, G., and Collins, M. B.: The influence of clay on the threshold of movement in fine sandy beds, Coast. Eng., 32, 19-43, 1997.

Parsons, D. R., Schindler, R. J., Hope, J. A., Malarkey, J., Baas, J. H., Peakall, J., Manning, A. J., Ye, L., Simmons, S., Paterson D. M., Aspden, R. J., Bass, S, J., Davies, A. G., Lichtman, I. D., and Thorne, P. D.: The role of biophysical cohesion on subaqueous bed form size, Geophys. Res. Lett., 43, 1566-1573, https://doi.org/10.1002/2016GL067667, 2016.

Paterson, D. M., Crawford, R. M., and Little, C.: Subaerial exposure and changes in the stability of intertidal estuarine sediments, Es- 
tuar. Coast. Shelf S., 30, 541-556, https://doi.org/10.1016/02727714(90)90091-5, 1990.

Pilditch, C. A., Widdows, J., Kuhn, N. J., Pope, N. D., and Brinsley, M. D.: Effects of low tide rainfall on the erodibility of intertidal cohesive sediments, Cont. Shelf Res., 28, 1854-1865. https://doi.org/10.1016/j.csr.2008.05.001, 2008.

Ralston, D. K., Geyer, W. R., and Warner, J. C.: Bathymetric controls on sediment transport in the Hudson River estuary: Lateral asymmetry and frontal trapping, J. Geophys. Res., 117, C10013, https://doi.org/10.1029/2012JC008124, 2012.

Rinehimer, J. P., Harris, C. K., Sherwood, C. R., and Sanford, L. P.: Sediment consolidation in a muddy, tidally-dominated environment: Model behavior and sensitivity, in: 10th International Conference on Estuarine and Coastal Modeling, 57 November 2007, Newport, Rhode Island, USA, 819-838, https://doi.org/10.1061/40990(324)44, 2008.

Sanford, L. P.: Modeling a dynamically varying mixed sediment bed with erosion, deposition, bioturbation, consolidation, and armoring, Comput. Geosci., 34, 1263-1283, 2008.

Sanford, L. P. and Maa, J. P. Y.: A unified erosion formulation for fine sediments, Mar. Geol., 179, 9-23, 2001.

Shchepetkin, A. F. and McWilliams, J. C.: The Regional Oceanic Modeling System (ROMS): A Split-Explicit, Free-Surface, Topography-FollowingCoordinate Oceanic Model, Ocean Model., 9, 347-404, https://doi.org/10.1016/j.ocemod.2004.08.002, 2005.

Sherwood, C. R., Drake, D. E., Wiberg, P. L., and Wheatcroft, R. A.: Prediction of the fate of p,p'-DDE in sediment on the Palos Verdes shelf, California, USA, Cont. Shelf Res., 22, 1025-1058, 2002.

Slade, W. H., Boss, E. S., and Russo, C.: Effects of particle aggregation and disaggregation on their inherent optical properties, Opt. Express, 19, 7945-7959, 2011.

Smoluchowski, M.: Versuch einer mathematischen theorie des koagulations-kinetik kolloid losungren, Zeitschrift fur Physikalische Chemie, 92, 129-168, 1917.

Soulsby, R. L., Manning, A. J., Spearman, J., and Whitehouse, R. J. S.: Settling Velocity and Mass Settling Flux of Flocculated Estuarine Sediments, Mar. Geol., 339, 1-12, https://doi.org/10.1016/j.margeo.2013.04.006, 2013.

Spearman, J. and Manning, A. J.: On the significance of mud transport algorithms for the modelling of intertidal flats, Chapter 28, in: Proceedings in Marine Science, Sediment and Ecohydraulics, edited by: Kusuda, T., Yamanishi, H., Spearman, J., and Gailani, J. Z., Elsevier, https://doi.org/10.1016/S1568-2692(08)80030-7, 411-430, 2008

Spearman, J. R., Manning, A. J., and Whitehouse, R. J. S.: The settling dynamics of flocculating mud-sand mixtures: Part $2-\mathrm{Nu}$ merical modelling, Ocean Dyn., 61, 351-370, 2011.

Stone, M., Krishnappan, B. G., and Emelko, M. B.; The effect of bed age and shear stress on the particle morphology of eroded cohesive river sediment in an annular flume, Water Res., 42, 41794187, https://doi.org/10.1016/j.watres.2008.06.019, 2008.

Swift, D. J. P., Stull, J. K., Niedoroda, A. W., Reed, C. W., Wong, G. T. F., and Foyle, B. A.: Estimates of the Biodiffusion Coefficient, DB, from Composition of the Benthic Infaunal Community, Report prepared for the Los Angeles County Sanitation Districts, Contribution No. 5 of the Sediment Dynamics Laboratory, Old Dominion University, Norfolk, Virginia, 1994.
Swift, D. J. P., Stull, J. K., Niedoroda, A. W., Reed, C. W., and Wong, G. T. F.: Contaminant dispersal on the Palos Verdes continental margin: II. Estimates of biodiffusion coefficient, Db, from composition of the benthic infaunal community, Sci. Total Environ., 179, 91-107, 1996.

Tambo, N. and Watanabe, Y.; Physical characteristics of flocs. I The floc density function and aluminium floc, Water Res., 13, 409419, 1979.

Tassi, P. and Villaret, C.: SISYPHE v6.3 User's Manual, EDF, Laboratoire National d'Hydrulique et Environnement, Chatou, France, 73 pp., 2014.

Thorne, P. D., MacDonald, I. T., and Vincent, C. E.: Modelling acoustic scattering by suspended flocculating sediments, Cont. Shelf Res., 88, 81-91, https://doi.org/10.1016/j.csr.2014.07.003, 2014.

Tolman, H. L. and the WAVEWATCH III Development Group: User manual and system documentation of WAVEWATCH III version 4.18, Technical Note, Environmental Modeling Center, National Centers for Environmental Prediction, National Weather Service, National Oceanic and Atmospheric Administration, U.S. Department of Commerce, College Park, MD, 2014.

van der Wegen, M., Dastgheib, A., Jaffe, B. E., and Roelvink, D.: Bed composition generation for morphodynamic modeling: case study of San Pablo Bay in California, USA, Ocean Dynam., 61, 173-186, https://doi.org/10.1007/s10236-010-0314-2, 2011.

van Ledden, M., van Kesteren, W. G. M., and Winterwerp, J. C.: A conceptual framework for the erosion behaviour of sand - mud mixtures, Cont. Shelf Res., 24, 1-11, https://doi.org/10.1016/j.csr.2003.09.002, 2004.

van Leussen, W.: Estuarine macroflocs and their role in fine-grained sediment transport, $\mathrm{PhD}$ thesis, University of Utrecht, Utrecht, The Netherlands, 1994.

van Leussen, W.: Aggregation of Particles, Settling Velocity of Mud Flocs A Review, in: Physical Processes in Estuaries, Springer, Berlin, Heidelberg, 347-403, https://doi.org/10.1007/978-3-64273691-9_19, 1988.

Verney, R., Lafite, R., Brun-Cottan, J. C., and Le Hir, P.: Behaviour of a floc population during a tidal cycle: Laboratory experiments and numerical modeling, Cont. Shelf Res., 31, S64-S83, https://doi.org/10.1016/j.csr.2010.02.005, 2011.

Villaret, C., Hervouet, J.-M., Kopmann, R., Merkel, U., and Davies, A. G.: Morphodynamic modeling using the Telemac finite-element system, Comput. Geosci., 53, 105-113, https://doi.org/10.1016/j.cageo.2011.10.004, 2011.

Warner, J. C., Sherwood, C. R., Signell, R. P., Harris, C. K., and Arango, H. G.: Development of a three-dimensional, regional, coupled wave, current, and sediment-transport model, Comput. Geosci., 34, 1284-1306, 2008.

Warner, J. C., Armstrong, B., He, R., and Zambon, J. B.: Development of a coupled ocean-atmosphere-wave-sediment transport (COAWST) modeling system, Ocean Model., 35, 230-244, https://doi.org/10.1016/j.ocemod.2010.07.010, 2010.

Wheatcroft, R. A. and Martin, W. R.: Spatial variation in short-term $\left({ }^{234} \mathrm{Th}\right)$ sediment bioturbation intensity along an organic-carbon gradient, J. Mar. Res., 54, 763-792, 1996.

Whitehouse, R. J. S., Soulsby, R. L., Roberts, W., and Mitchener, H.: Dynamics of Marine Muds, Thomas Telford, London, 2000.

Wiberg, P. L., Drake, D. E., and Cacchione, D. A.: Sediment resuspension and bed armoring during high bottom stress events 
on the northern California inner continental shelf: measurements and predictions, Cont. Shelf Res., 14, 1191-1219, 1994.

Winterwerp, J. C.: A simple model for turbulence induced flocculation of cohesive sediment, J. Hydraulic Res., 36, 309-326, https://doi.org/10.1080/00221689809498621, 1998.

Winterwerp, J. C.: On the Dynamics of High-Concentrated Mud Suspensions, Technical University of Delft, Delft, The Netherlands, 1999.

Winterwerp, J. C.: On the flocculation and settling velocity of estuarine mud, Cont. Shelf Res., 22, 1339-1360, 2002.

Winterwerp, J. C. and Kranenburg, C. (Eds.): Fine Sediment Dynamics in the Marine Environment, Proceed. Marine Sci., Vol. 5, Elsevier, Amsterdam, 2002.

Winterwerp, J. C. and van Kesteren, W. G. M.: Introduction to the Physics of Cohesive Sediment in the Marine Environment, Elsevier, Amsterdam, 2004.

Winterwerp, J. C., Bale, A. J., Christie, M. C., Dyer, K. R., Jones, S., Lintern, D. G., Manning, A. J., Roberts, W., and Kranenburg, C.: Flocculation and settling velocity of fine sediment, Proceed. Marine Sci., 5, 25-40, 2002.
Winterwerp, J. C., Manning, A. J., Martens, C., de Mulder, T., and Vanlede J.: A heuristic formula for turbulence-induced flocculation of cohesive sediment, Estuar. Coast. Shelf S., 68, 195-207, 2006.

Winterwerp, J. C., Maa, J. P.-Y., Sanford, L. P., and Schoellhamer, D. H.: On the sedimentation rate of cohesive sediment, Proceed. Marine Sci., 8, 209-226, 2007.

$\mathrm{Xu}, \mathrm{F}$. , Wang, D.-P., and Riemer, N.: Modeling flocculation processes of fine-grained particles using a size-resolved method: Comparison with published laboratory experiments, Cont. Shelf Res., 28, 2668-2677, https://doi.org/10.1016/j.csr.2008.09.001, 2008.

$\mathrm{Xu}$, F., Wang, D.-P., and Riemer, N.: An idealized model study of flocculation on sediment trapping in an estuary turbidity maximum, Cont. Shelf Res., 30, 1314-1323, https://doi.org/10.1016/j.csr.2010.04.014, 2010. 